This item was submitted to Loughborough's Research Repository by the author.

Items in Figshare are protected by copyright, with all rights reserved, unless otherwise indicated.

\title{
Preparation of nanoclay embedded polymeric membranes for the filtration of natural organic matter (NOM) in a circular crossflow filtration system
}

PLEASE CITE THE PUBLISHED VERSION

https://doi.org/10.1016/j.jwpe.2020.101408

\section{PUBLISHER}

Elsevier

VERSION

AM (Accepted Manuscript)

\section{PUBLISHER STATEMENT}

This paper was accepted for publication in the journal Journal of Water Process Engineering and the definitive published version is available at https://doi.org/10.1016/j.jwpe.2020.101408.

LICENCE

CC BY-NC-ND 4.0

\section{REPOSITORY RECORD}

Seshasayee, MS, Z Yu, G Arthanareeswaran, and Diganta Das. 2020. "Preparation of Nanoclay Embedded Polymeric Membranes for the Filtration of Natural Organic Matter (NOM) in a Circular Crossflow Filtration System". Loughborough University. https://hdl.handle.net/2134/12407564.v1. 
Preparation of nanoclay embedded polymeric membranes for the filtration of natural organic matter (NOM) in a circular crossflow filtration system

\author{
M. S. Seshasayee ${ }^{a}$, Z. Yu ${ }^{b}$, G. Arthanareeswarana, ${ }^{a, *}$ D. B. Das ${ }^{\text {b,* }}$ \\ ${ }^{a}$ Membrane Research Laboratory, Department of Chemical Engineering, National Institute \\ of Technology, Tiruchirappalli-620015, Tamil Nadu, India \\ ${ }^{b}$ Department of Chemical Engineering, Loughborough University, Loughborough LE11 3TU, \\ Leicestershire, UK
}

*Corresponding author (E-mails address: arthanaree10@yahoo.com, D.B.Das@lboro.ac.uk) 


\section{Abstract}

In-house and commercial membranes were used with different properties for humic acid separation in a circular crossflow filtration system to determine the membranes' performances. The in-house membranes were fabricated with the addition of bentonite nanoclay in Mendall, polyvinylidenefluoride (PVDF), polyphenylsulfone (PPSU), polysulfone (PSF) and polyether sulfone (PES) polymers. Bentonite nanoclay is recognized as a promising material for membrane applications due to its ability to produce membranes with superior properties such as the mechanical strength, large surface areas, adsorbing, antifouling and well-defined pore morphology. Three types of commercial membranes were also used for humic acid removal from water. The morphology, surface roughness, porosity and average pore size of the in-house and commercial membranes were then compared. The XM50 commercial membranes showed smooth and even surface topography as compared to other commercial and in-house membranes. The addition of bentonite into the polymer changed the morphological structure, surface roughness, pore size of the polymeric membranes. Pure water flux, permeate flux and rejection of humic acid were compared for in-house polymeric membranes and commercial membranes in a circular crossflow filtration system. It was observed that the fouling of humic acid was reduced by the addition of bentonite nanoclay in the in-house polymeric membranes.

Keywords: Membrane filtration; membrane fouling; nanoclay; water purification; circular crossflow channel

\section{Introduction}

Increasing industrialization has had an adverse impact on natural resources affecting the quality of drinking water sources. The decreased availability of water has forced the humans to utilize wastewater for drinking purpose after removal of pollutant and efficient water treatment [1, 2]. Natural organic matter (NOM) such as humic acid is available in surface water which causes several 
issues such as colour, taste, odour and health problems. Membrane separation serves as a good solution to solve these issues by providing an effective treatment and removal of humic acid. The choice of the membrane materials in this regard is crucial as they can address the issue of fouling caused by the pollutants from wastewater which otherwise may limit or stop the application of membrane separation in such cases [3]. Hence, modifications to the membrane materials, either on the surface or the internal morphology relating to the pore space, could help to enhance the membrane performances and control membrane fouling [4]. A number of polymer and biopolymer materials such as cellulose acetate (CA) [5], chitosan [6], polyvinylidenedifluoride (PVDF) [7], polyphenylsulfone [8], polysulfone [9], polyethersulfone [10] have been developed already by surface modification for removal of natural organic matter (NOM) like humic acid. PVDF is used as a membrane material for ultrafiltration for humic acid separation because of its outstanding properties of resistance towards chemical and membrane formation ability [7]. The antifouling property has been studied using humic acid solution for modified polyphenylsulfone by polydopamine coating ultrafiltration membrane [8]. Silica derived from rice husk and used as a modifier in the polysulfone membrane for antifouling performance [9]. In this work, humic acid solution has been identified as a major foulant for natural organic matter (NOM) for effective study of antifouling performance. Polyethersulfone membranes were modified with hydrophilic monomers by phase inversion for removal of humic acid [10]. A number of other investigations have also been done to modify the PVDF, PPSU, PSf and PES membranes for effective removal and antifouling performance using NOM. Literature reported that bentonite nanoclay was used as modifiers in membrane fabrication [11-20]. Bentonite clay has smectite group with an arrangement of aluminium-phyllosilicate with tetrahedral silica and octahedral alumina layers. Broadly, it is used in the wastewater treatment as an adsorbent material. In an ore of clay, the main constitute of clay is found to be montmorillonite. Membrane modifier like nanoclay (bentonite) has been proved to increase pore size, hydrophilic, antifouling property in polymeric membranes, which has also increased the water permeate flux through the membranes [12]. Naturally available nanoclay is therefore a potential modifier for the 
polymer for water purification, which provides strong hydrophilicity, good chemical and mechanical strengths with low cost. Panpanit and Visvanathan [13] reported that the addition of bentonite in cellulose acetate has directed to enhanced hydrophilicity, porosity, permeability, antifouling property and effective control of the surface membrane properties. The addition of nanoclay increases the hydrophilic property of PVDF membrane and increase the water permeate flux through the membrane $[14,15]$. The nanoclay can also increase the mechanical strength and thermal stability of the membranes [16-18]. According to the literature, nanoclay can control the porous morphologies within the membranes that can increase the clean water flux through the membranes $[19,20]$. The reason for the use of bentonite nanoclay for humic acids removal is constant ionic strength, bridging of bivalent metal ions between clay and humic acid. Furthermore, the dominant adsorption mechanism favours the removal of humic acid and enhancement of water flux. Hence, bentonite nanoclay was chosen for this study for polymer modification due to its low cost, antifouling property, hydrophilicity and removal of humic acid was not reported using bentonite nanoclay in all polymeric membranes.

In the present work, the fabricated in-house polymeric membranes with nanoclay were compared with the performance of commercial membranes to determine their performance in water and humic acid separation. Most of the current processes for the separation of humic acid are based on dead-end filtration which typically lead to concentration polarization and fouling. In dead-end mode, the flow of fluid is perpendicular to the filtration, so that water passes through the membranes while the solute particles are retained on the membrane surface, clogging and blocking the surface [21,22]. To overcome the blocking of dead-end filtration, a circular crossflow filtration system is used for NOM filtration in this work. The crossflow filtration system used to conduct all filtration experiments is discussed in previous studies in detail $[23,24]$. In the system, both Taylor and Dean vortices are formed, which help in reducing the concentration polarization and membrane fouling by producing secondary flows $[23,24]$. This paper aims to study the flux, rejection of humic acid and fouling effects of nanoclay embedded in-house polymeric membranes and commercial membranes in the same 
crossflow filtration system $[23,24]$. The major issue faced by most crossflow systems is low contact time. Hence, the fluidic channels in the system where small fluid fluctuations are observed due to the increased surface effects are characteristics of the length-scale of the channel. The decreased velocity of fluid across the crossflow filtration system increases the contact time of the fluid with the membranes. Therefore, the main attempt in this work was based on the fabrication in-house membranes by addition of nanoclay in polymer blends, compare their performances with commercial membranes in circular crossflow filtration for permeate flux, humic acid solute rejection and fouling behaviour.

\section{Experiment}

\subsection{Materials}

The analytical grade polyvinylidene fluoride (PVDF), polyphenylsulfone (PPSU), polyamide-imides (PAI) and polysulfone (PSF), polyether sulfone (PES) (3000p) were purchased from Solvay Specialty Polymers Ltd, India. N-methyl-2-pyrrolidone (NMP), sodium dodecyl sulfate (SDS) (surfactant) was obtained from Merck Specialties Ltd., India. $\mathrm{K}^{+}$- Bentonite nanoclay was purchased from SigmaAldrich India limited. A sample SEM image of the bentonite nanoparticles is shown in Fig. 1. Commercial membranes (PM10, XM300, XM50) were purchased from Amicon ${ }^{\mathrm{TM}}$ (Massachusetts, USA). Humic acid particles were procured from M/s. Loba Cheme, India. Double distilled (DD) water was prepared in the laboratory for use in all experiments.

\subsection{Fabrication of nonoclay based in-house polymeric membranes}

Nanoclay embedded polymeric membranes were prepared by phase inversion process. The fabrication procedure is described below, which is also shown schematically in Fig. 2. 
The dope polymer solution was prepared with $16.5 \%$ polymers, $1 \%$ nanoclay, and $82.5 \%$ solvent on a weight basis. N-methyl-2-pyrrolidine (NMP) was used as the solvent and bentonite was used as the nanoclay for the membrane modification. The nanoclay size ranges between $50-250 \mathrm{~nm}$ with an average particle diameter of $179 \mathrm{~nm}(\mathrm{SD}: \pm 79 \mathrm{~nm})$. The in-house polymeric membranes were fabricated with polyether sulfone (PES), polyvinylidene fluoride (PVDF), polyphenylsulfone (PPSU), polyamide imide (PAI), poly-sulfone (PSF). Sodium dodecyl sulfate was used as the surfactant during the membrane formation and was diluted with deionized water (DI) water at concentrations of $2 \%$. The $1 \mathrm{wt} \%$ bentonite and $82.5 \%$ NMP mixture was sonicated in an ultrasonic bath for $3 \mathrm{~h}$ to ensure uniform dispersion of the bentonite particulates in the solvent. $16.5 \%$ of all polymers was added individually into the complete dispersed bentonite and NMP mixture and accompanied by constant magnetic stirring at $400 \mathrm{rpm}$ for over $24 \mathrm{~h}$ using ultrasonicator (model: Bath sonicator, PCI Analytics). The homogeneous solution was then allowed to eliminate air bubbles in an hour. The solution is then cast into thin films of $250 \mu \mathrm{m}$ thickness over a clean, leveled glass plate using a stainless-steel film applicator at $50 \%$ humidity and $25^{\circ} \mathrm{C}$ temperature. The film was kept for 30s to evaporate the solvent, then exposed to a surfactant bath at $15^{\circ} \mathrm{C}$ for $1 \mathrm{~h}$. The membranes are kept in water for $24 \mathrm{~h}$ before subsequent storage in formalin. The outline of the membrane fabrication process is shown in Fig. 2.

\subsection{Commercial membranes}

Commercial membranes were used to compare the performance of the in-house membranes developed in this work. XM300 and XM50 are modified polyacrylic fibrous membranes, while PM10 is a hydrophilic polysulfonic membrane.

\subsection{Membranes characterization}

In order to analyse the surface morphology of the membranes, SEM micrographs of the membrane surfaces and cross-sections were obtained by using a field emission gun scanning electron microscope 

FEG-SEM (Leo (Zeiss) 1530-VP) equipped with X-ray energy dispersive spectroscopy (X-EDS) system. The membranes were coated with a gold-palladium sputter coating prior to the analysis. The SEM accelerating the voltage was set at $20 \mathrm{kV}$ and the images were procured at $1 \mathrm{kX}, 10 \mathrm{kX}$ and $25 \mathrm{kX}$ magnifications. The pore radii and fiber characteristics of the membranes were calculated by processing the SEM micrographs (Table 1). The elemental compositions of the surface of the membranes were analyzed using X-ray energy dispersive spectroscopy (EDS) before and after the filtration process. The composition of the debris after the filtration experiments gives an insight into the performance of the membrane. The SEM micrographs were therefore analysed further with the help of an image processing software, namely ImageJ 1.38e, Adobe Photoshop CC 2015, and MATLAB R2016a, to calculate the membrane porosity values [25]. The porosities calculated from the image processing step are supplemented with experimental results. A $1 \mathrm{~cm}^{2}$ cut was made on the membranes, which was then kept in an ultrasonic bath in distilled water for $30 \mathrm{~min}$. The weights of the membranes were immediately measured after they were taken out of the water bath, and the wet weights of the membranes are obtained. The membranes are then dried for a day under ambient conditions. The membrane weights measured provided the dry weight of the membranes. The porosity of the membranes $(\varepsilon)$ is calculated according to equation [26],

$$
\varepsilon=\frac{\left(w_{1}-w_{2}\right) / \rho_{\text {water }}}{w_{2} / \rho_{\text {membrane }}+\left(w_{1}-w_{2}\right) / \rho_{\text {water }}}
$$

where $w_{1}$ is the total weight of the membrane and liquid in the membrane, $w_{2}$ is the weight of the dried membrane, $\rho_{\text {water }}$ is the density of water, $\rho_{\text {membrane }}$ is the density of the membrane.

The overall surface roughness and 3D morphology were studied by using Veeco Explorer AFM (now owned by Bruker Corp) at tapping mode (TM-AFM) using a silicon probe at a high resonance frequency. The surface roughness was expressed by a root-mean-square roughness while the average roughness was calculated by the following equations:

$$
R_{a}=\frac{1}{n} \sum_{i=1}^{n}\left|y_{i}\right|
$$




$$
R_{r m s}=\sqrt{\frac{1}{n} \sum_{i=1}^{n} y_{i}^{2}}
$$

where $R_{a}$ is average roughness, $R_{r m s}$ is the root mean square roughness, $n$ is the number of points in the sample area, $y_{i}$ is the surface height. The scanning area of each membrane was $10 \mu \mathrm{m} \times 10 \mu \mathrm{m}$. It is assumed that the chosen sample surface $(10 \mu \mathrm{m} \times 10 \mu \mathrm{m})$ represents the surface of the membrane. The calculated data indicate the roughness on the membrane surfaces, as discussed in Section 3.

\subsection{Membrane filtration performance}

\subsubsection{Circular crossflow filtration cell}

Filtration experiments are conducted (Fig. 3(a)) to measure the flow and rejection characteristics of humic acid through the chosen membranes. The circular crossflow filtration cell (600 mL volume) purchased from AMICON, Massachusetts, USA has an effective membrane surface area of $40 \mathrm{~cm}^{2}$. The flow in the cell is achieved by a peristaltic pump which is acquired from Watson-Marlow Ltd, Cornwall, UK. The system is pressurized by compressed air and controlled using manual control valves. A humic acid solution is maintained as a homogenous suspension by utilizing a stirrer. The pressurized feed (Fig. 3(b)) enters the filtration cell and flows through a circular crossflow channel consisting of 3 spirals. The channels have a maximum radius of $4.1 \mathrm{~cm}$ and a minimum radius of 1 $\mathrm{cm}$. The spiral fluidic channel was characterized, and the structure of the channel was determined using surface metrology. A coordinate measuring instrument, Talysurf CLI 2000 (LK ultra-Carnio studio), was used to determine the geometry of the system (Fig. 4). The width, height, and length of the channel and the conical height of the device are measured. These are found to be $9.5 \pm 0.3 \mathrm{~mm}$, $0.363 \pm 0.005 \mathrm{~mm}$ and $760 \mathrm{~mm}$, respectively. The feed entering the spiral channel flows through the membrane under the channel, which rejects a fraction of the feed while allowing a part to permeate through it. The retentate is recycled back to the feed reservoir. The pressure gauges are utilized to measure the pressure at feed inlet, retentate outlet, permeate outlet, and channel inside. 


\subsubsection{Permeate flux of humic acid}

Steady states are attained for the membranes at around $20 \mathrm{~min}$. The flux of the system is calculated according to the equation [23]:

$$
\text { Permeate Flux }=\frac{\text { Permeate Volume }}{\text { Time } \times \text { Effective Membrane Area }}
$$

The rejection $\%$ of the membranes for the system was analyzed by calculating the concentration of humic acid in the permeate. The permeate concentrations are determined using a spectrophotometer (model: mini 1240 UV-VIS, Shimadzu, Milton Keynes, UK), which measures the absorbance at a wavelength of $254 \mathrm{~nm}$. The permeate concentrations are calculated with the prepared humic acid solutions as the standard. The turbidity of the solutions was obtained using a $\mu$ TPW turbidity meter.

\subsubsection{Fouling studies}

The clean membranes are pretreated by soaking in deionized water for one hour, with water being replenished every $20 \mathrm{~min}$. The feed is sonicated using an ultrasonic water bath for about $60 \mathrm{~min}$ at $22^{\circ} \mathrm{C}\left( \pm 2^{\circ} \mathrm{C}\right)$ to homogenize the humic acid solution. The membranes are carefully placed under the circular crossflow channel with the glossy side facing up. The peristaltic pump is utilized to initiate a constant velocity flow in the filtration cell. The pressure of the feed inlet is controlled manually by using a pressure value. The filtration was run for $80 \mathrm{~min}$, and samples of permeate are collected at regular intervals of $2 \mathrm{~min}$. The pressure of the system is altered every $20 \mathrm{~min}$ where it is initially kept at 1 bar, then raised to 1.5 bars before decreasing it back to 1 bar and then subsequently increasing again. Filtration experiments are performed for all the membranes. A $40 \mathrm{mg} / \mathrm{L}$ solution of humic acid is prepared to run in the filtration system. The humic acid concentration in the feed was chosen based on typical free carbon content of in rivers [27]. 


\section{Results and Discussion}

\subsection{Morphologies of in-house and commercial membranes}

The surface and cross-sectional morphologies of the in-house and commercial membranes are shown in Fig. 5, 6 and 7. It is evident that $1 \mathrm{wt} . \%$ bentonite in polymers changed the morphologies of the inhouse membranes. All polymeric membranes showed macroporous and microporous pores on the surface of the membrane. The overall membrane surface morphologies were also significantly affected by the addition bentonite. In particular, the pore formation and pore size were found to be enhanced for PSf and PES polymeric membranes. As depicted in Fig. 5, the top surface of Mendall polymer has a denser pore structure, which is due to the delayed de-mixing during the phase inversion process. In Fig. 5, the surface of membranes through the SEM images indicate that the all membranes are well tailored by bentonite nanoclay.

It is evident that nanoclay membrane morphology is characterized by a superficial layer with macropore, a bottom layer which has a sponge-like pore structure with micro-pores and an intermediate layer, with finger-like pores and micro-pores [28]. Membranes are found to have an elongated fingerlike macroporous structure followed by a sponge-like microporous structure (Fig. 6). This provides improvement to the high rejection, which is observed in the membranes due to the compacted nature of the small microporous layer. However, Mendall ${ }^{\mathrm{TM}}$ polysulfone is found to have a wafer-like spongy microporous structure. This leads to a high flow rate since the micropores present in the membrane are large. It is also observed that all the porous membranes except Mendall ${ }^{\mathrm{TM}}$ polysulfone have a pore size that are in the ultrafiltration range. Hence, these membranes show a large rejection percentage for the humic acid particles, which is composed of particles in the size range of $0.1-100$ $\mu \mathrm{m}$. The crossflow nature of the flow causes the water to seep through the layers of membranes and seem to thicken them, most likely, due to their hydrophilic nature. A change in the pore structures is also observed (Fig. 6) due to the presence of large macropores in the membranes. A reduction in the 
size of the pores is observed due to the encapsulation of pores resulting from fluid flow. This further explains the reason as to why the rejection is found to increase with pressure.

As observed in Table 1, the average pore size of the membranes increases due to the addition of nanoclay. This is likely to affect the fouling and, hence, the filtration efficiencies of the membranes, as well as other factors such as their wetting characteristics. We discuss how the addition of nanoclay affects the fouling and filtration efficiencies of the membrane in the latter part of the paper. However, this work did not carry out any measurements on the wetting characteristic of the membrane during the filtration experiments. This is because we are of the opinion that the typical ex-situ measurements techniques for wetting characteristic (e.g., contact angles) may not represent the in-situ conditions within the filtration set up closely enough.

\subsection{EDS mapping of in-house membranes}

The presence of bentonite nanoclay in the membrane structure was confirmed by energy-dispersive X-ray spectroscopy (EDS) mapping (Fig. 8). Silicon (due to the presence of nanoclay particles), aluminum, sodium, magnesium, potassium, titanium and iron were observed in the polymeric membrane structure. Bentonite is a clay mineral which consists of aluminum silicates, iron, magnesium, sodium, potassium, and iron. Hence, most of the elements on the membrane surface were carbonaceous or metal ions. These are accumulated due to irregularities on the polymer surface, storage of membranes in water, and facilitate the adsorption of humic acid and transport water through the membranes. It is also verified that the elemental composition of the initial concentration of polymer solution and that of the final membrane manufactured are similar, showing homogeneity exhibited by the membrane manufacturing process.

\subsection{Porosity values of in-house and commercial membranes}


The porosity values of the membranes calculated through membrane weighing and image processing method are illustrated in Fig. 9. The measured porosity of XM 30 membrane has the highest value when compared with other membranes. For all in-house membranes, PSf membrane has the highest value when compared. The higher porosity of the membranes is attributed to the delayed solidification, solubility parameters of the non-solvent-polymer system. Hence, the porosity of the membranes can be controlled by bentonite nanoclay in polymeric membranes e.g. the coagulation. However, the porosity measurement by image processing and wet method are varying the values of all the membranes. The nanoclay particles are dispersed in the DMF solvent. When the polymer solution and clay suspensions are mixed, the polymer chains intercalate and displace the solvent within the interlayer of the clay, which then evaporates [29]. As seen in SEM images, the addition of nanoclay results in membranes with thinner skin layer and higher porosity when compared with polymeric membranes. Water flux of nanoclay embedded membranes also increases significantly [30]. In some of the cases, where the membrane surfaces have prominent 3D surface topologies (e.g., PAI and PSF), the image processing tool may not provide a very accurate interpretation of the porosity values. This is evident in Fig. 9.

\subsection{Surface roughness of in-house and commercial membranes}

AFM is useful and versatile tool for membrane surface characterisation. The surface roughness of inhouse membranes was analysed from AFM images and are shown in the supporting information SFig. 1. The images show the distribution of the nanoclay particles on the surface of the membranes, indicated by the white spots which represent the nanoclay particles. The nodular surface morphology in the images also suggest that the nanoclay particles are dispersed fairly uniformly in the polymer blend promoting a uniform enhancement of roughness throughout the membrane surface. The surface roughness is considered as a measure of fouling of the membrane surface. Mendall ${ }^{\mathrm{TM}}$ polysulfone is found to have the largest roughness factor, which amounts to a high degree of fouling on its surface, as seen above. Statistical analyses show the average roughness of the commercial membranes from 
the AFM images which are included in the supporting information (S-Fig. 2). The commercial membranes are found to have marginally smoother surface as compared to the in-house membranes. The $3 \mathrm{D}$ views of AFM images of the in-house and commercial membranes are shown in Fig. 10 and 11. All the images showed the changes of membrane physical structure of the surface and roughness. The addition of nanoclay in the polymers network changes in surface roughness with alteration of physical surface profile. In particular, when the Psf membranes were modified with nanoclay, the pore-diameters were observed to become larger. The root-mean-square of the roughness and average roughness factors were calculated and shown in Fig. 12. As evident the roughness increases due to the surface area of clay particles. In particular, the PSf membranes showed higher root-mean-square roughness and average roughness values. The reason for the increase in the roughness is mainly due to the hydrophobicity of the PSf membranes [31]. Furthermore, the bentonite being more loosely packed during the casting conditions, it leads to greater surface roughness. Hence, the fouling are reduced during the use of in-house membranes as compared with the existing commercially available membranes. These roughness results confirmed the efficacy of the in-house membranes in cleaning, removing foulant and adsorbent from membrane surfaces. The rougher surfaces fouled more most likely due to the effects of increased colloidal interactions and adsorption on the membrane surface.

\subsection{Humic acid separation performances of in-house and commercial membranes}

Humic acid flux and rejection experiments were conducted for PVDF, PES, Mendall membranes and commercial membranes on the circular crossflow systems. The dry humic acid particles and particle size range is shown in Fig. 13. Among the commercial membranes, XM 300 showed higher permeate flux for humic acid solution (Fig. 14 (b)). In the case of in-house membranes, Mendall-bentonite membrane showed higher permeate flux for humic acid solution (Fig. 14 (a)). As shown in Fig. 15 later, the higher humic acid rejection was found for PVDF-bentonite and PM 10 membranes. There are the two key factors for higher rejection, one is size exclusion of humic acid with respect to the shapes and hydrodynamic sizes. Next, the increase of repulsion between humic acid and bentonite 
incorporated PVDF membranes. Porous membranes (Mendall ${ }^{\mathrm{TM}}$ polysulfone) that have large flux are found to have the least rejection, whereas polyvinylidene fluoride is found to have the highest rejection suffers from the lowest flux. Permeate flux is found to be more in the case of clean water than the humic acid due to the accumulation of humic acid particles on the surface of the membranes. These particles cause a net decrease in the porous nature of the membranes, which in turn curbs the flow of flux through the system. It is ascertained from the experiments that as the size of pores increase, the flux through the membranes increases, and the rejection decreases. This is due to the increase in pore size of membranes allowing more flux as well as larger particles to pass through the membrane. According to the literature, humic acid have monodisperse particle and they may contain a central "core" with a different structure [32]. The interaction of bentonite and humic acid from the aqueous solutions for humic acid removal was reported for polyacrylamide/bentonite composites [33].

\subsection{Fouling behavior of in-house and commercial membranes}

The fouling studies of the in-house and commercial membrane were conducted using humic acid solution and demineralised water. The fouling experiments were carried out with reference to the fluxes of humic acid and water through the membrane. As shown in Fig. 14 (a and b), the permeate flux of step two is found to differ from that of step one. This change in flux is due to a change in the pore characteristics that are attributed to multiple factors such as the accumulation of particles on the membrane surface and the effects of the momentum of fluid flow through the pores. Most membranes have a constant flux during the filtration process during step I and step II. Membranes are found to attain a steady-state flux within the $20 \mathrm{~min}$ of the experiment. Hence, the circular crossflow filtration system could effectively reduce particle accumulation on the surface of the membrane, which protects the membranes against fouling (which would cause a decrease in flux). However, Mendall ${ }^{\mathrm{TM}}$ polysulfone has a significant decrease in flux. This is attributed to the high flux characteristics due to which the momentum of the water particles can cause a more significant decrease in flow over time. 
As mentioned above, the observations could be explained by the change in the pore size of the membranes. High pressure increases the momentum of fluid on the surface of the membranes, in turn, increasing the pore size of the membrane. It is also observed that time has an inertial effect on the membrane pore structures. When the pressure is reverted to 1 bar (run 1) after operating in 1.5 bar (run 2), the flux increases. This is because the pore sizes remain in their original sizes (as when the system is started). Ahmad et al [34] investigated the effect of membrane morphology, pore size, and porosity on fouling behavior of humic acid solution through PES membrane with different loadings of $\mathrm{TiO}_{2}$ as the nano material. It is concluded that the strength of pores and their resistance to shear forces is pivotal to the efficiency of the membranes. The more resilient the pore is to changes in its surroundings, the longer the life of the membrane. Fouling of membrane is another factor to be minimized, that directly reduces the flow of the membrane. The humic acid flux of PES-bentonite membrane was significant dependence on pore size of the membrane. However, the humic acid deposits and tighter packing of the humic acids within the deposit on surface of the membrane may cause the decline of flux during cross flow filtration.

\subsection{Turbidity of the permeate from using in-house and commercial membranes}

The turbidity of humic acid in permeate through in-house and commercial membranes was compared with 1 and 1.5 bar pressure in cross flow filtration. This is illustrated in Fig. 16 which shows the change in turbidity of membranes as a function of pressure. It is seen that PM10 and PVDF membranes had lower turbidity in permeate in both 1 and 1.5 bar pressure. The rejection percentage was further correlated with the turbidity of the solution. The turbidity of the permeate means that humic acid substances passes through the membrane in the permeate. The bentonite incorporated Mendall membrane is having average pore size of $8.375 \mu \mathrm{m}$ which is higher than other membranes (Table 1). The permeate flux for humic acid is also higher than other membranes. When humic acid solution was passed through the crossflow filtration system, humic acid molecules were adsorbed on the membrane surface due to the presence of bentonite. As an example, the adsorbed humic acid on 
the Mendall membrane surface is shown in Fig. 17. At 1 and 1.5 bar pressure, the humic acid particles transfer very fast through the internal pores of Mendall membrane. Hence, the Mendall membrane showed higher value of turbidity in the permeate. This is because the humic acid partially dissolves in water, it still contains a lot of suspensions which remain in the permeate. These suspensions cause the muddy brown color in the solution, which increases the turbidity.

\section{Conclusion}

It is found that the performance of the in-house nano-porous membranes is comparable to the performance of commercially available membranes. The in-house membranes show low fouling, high flux rate and low retention favoring their potential applications in water purification. Of the in-house membranes, a high average pore size of $8.375 \mu \mathrm{m}$ was observed for Mendall-bentonite membrane which is higher than all other in-house and commercial membranes. In addition, the surface and crosssectional morphology of membranes with different orientation in presence of nanoclay showed the impacts on humic acid separation in cross flow filtration. Bentonite in polymeric membranes was highly effective in changing the membrane surface roughness favouring the interactions of the membrane surface with humic acid particles. The chosen commercial membranes, namely, PM10, XM50 and XM300, had smother surface topography than the in-house membranes. From the fouling studies, it can be concluded that the introduction of the charged bentonite nanoclay for polymeric membranes modification with different surface roughness are the main targets to reduce undesirable fouling. Therefore, these membranes have prospects of being specialized for their specific application with the addition of nanoclay. Further analysis of a broader range of nanocomposite-based membranes is to be analyzed in the future. 


\section{Acknowledgments}

This work is supported under Newton-Bhabha Higher Education Initiative Fund (Grant Number: HEP151642) funded by Royal Academy of Engineering, UK. We acknowledge the helpful comments of two anonymous referees as well as the editor which helped to improve the clarity of the paper.

\section{References}

[1] Khajuria, A. "Impact of Nitrate Consumption: Case Study of Punjab, India". J. Water Resour. Prot. (2016) doi:10.4236/jwarp.2016.82017.

[2] TNPCB. "Groundwater Quality in SIPCOT Cuddalore - An Analysis of TNPCB Sample Results of Groundwater". http://www.sipcotcuddalore.com/downloads/GW_report_Cuddalore_Sept_2014.pdf (2014).

[3] Gao, W., Liang, H., Ma, J., Han, M., Chen, Z. lin, Han, Z. shuang and Li, G. bai. "Membrane fouling control in ultrafiltration technology for drinking water production: A review". Desalination (2011) doi:10.1016/j.desal.2011.01.051.

[4] Franken, A. C. M. "Prevention and control of membrane fouling : practical implications and examining recent innovations". Prev. Control Membr. Fouling (2009).

[5] Kanagaraj, Palsamy, Ibrahim MA Mohamed, Wei Huang, and Changkun Liu. "Membrane fouling mitigation for enhanced water flux and high separation of humic acid and copper ion using hydrophilic polyurethane modified cellulose acetate ultrafiltration membranes." Reactive and Functional Polymers (2020): 104538. doi: 10.1016/j.reactfunctpolym.2020.104538

[6] Darwish, Nawaf Bin, Hasan Al Abdulgader, Hamad AlRomaih, and Abdulrahman Alalawi. "Effect of ultrafiltration membranes modifications by chitosan on humic acid fouling." Journal of water process engineering 27 (2019): 32-36. doi: 10.1016/j.jwpe.2018.11.008

[7] Saraswathi, M. Sri Abirami, R. Kausalya, Noel Jacob Kaleekkal, D. Rana, and A. Nagendran. "BSA and humic acid separation from aqueous stream using polydopamine coated PVDF ultrafiltration membranes." Journal of environmental chemical engineering 5, no. 3 (2017): 
407 [8] Jamalludin, Mohd Riduan, Zawati Harun, Siti Khadijah Hubadillah, Hatijah Basri, Ahmad Fauzi 408

[11] Pagidi, Aruna, Y. Lukka Thuyavan, G. Arthanareeswaran, A. F. Ismail, Juhana Jaafar, and Diby Paul. "Polymeric membrane modification using SPEEK and bentonite for ultrafiltration of dairy wastewater." Journal of applied polymer science 132, no. 21 (2015)

[12] Morihama, A. C. D. and Mierzwa, J. C. "Clay nanoparticles effects on performance and morphology of poly(vinylidene fluoride) membranes". Brazilian J. Chem. Eng. (2014) doi:10.1590/S0104-66322014000100009.

[13] Panpanit, S. and Visvanathan, C. "The role of bentonite addition in UF flux enhancement mechanisms for oil/water emulsion". J. Memb. Sci. 184, 59-68 (2001) doi:10.1016/S03767388(00)00609-8.

[14] Liu, F., Du, C. H., Zhu, B. K. and Xu, Y. Y. "Surface immobilization of polymer brushes onto porous poly(vinylidene fluoride) membrane by electron beam to improve the hydrophilicity and fouling resistance". Polymer (Guildf). (2007) doi:10.1016/j.polymer.2007.03.033. 
[15] Zhao, Y. H., Qian, Y. L., Zhu, B. K. and Xu, Y. Y. "Modification of porous poly(vinylidene fluoride) membrane using amphiphilic polymers with different structures in phase inversion process". J. Memb. Sci. (2008) doi:10.1016/j.memsci.2007.11.040.

[16] Anadão, P., Sato, L. F., Wiebeck, H. and Valenzuela-Díaz, F. R. "Montmorillonite as a component of polysulfone nanocomposite membranes". Appl. Clay Sci. (2010) doi:10.1016/j.clay.2009.12.011.

[17] Lai, C. Y., Groth, A., Gray, S. and Duke, M. "Preparation and characterization of poly(vinylidene fluoride)/nanoclay nanocomposite flat sheet membranes for abrasion resistance". Water Res. (2014) doi:10.1016/j.watres.2014.03.005.

[18] Ma, Y., Shi, F., Wang, Z., Wu, M., Ma, J. and Gao, C. "Preparation and characterization of PSf/clay nanocomposite membranes with PEG 400 as a pore forming additive". Desalination (2012) doi:10.1016/j.desal.2011.10.040.

[19] Hwang, H. Y., Kim, D. J., Kim, H. J., Hong, Y. T. and Nam, S. Y. "Effect of nanoclay on properties of porous PVdF membranes". Trans. Nonferrous Met. Soc. China (English Ed. (2011) doi:10.1016/S1003-6326(11)61078-9.

[20] Lai, C. Y., Groth, A., Gray, S. and Duke, M. "Impact of casting conditions on PVDF/nanoclay nanocomposite membrane properties". Chem. Eng. J. (2015) doi:10.1016/j.cej.2014.12.036.

[21] Kim, A. S. and Hoek, E. M. V. "Cake Structure in Dead-End Membrane Filtration: Monte Carlo Simulations". Environ. Eng. Sci. 19, 373-386 (2002) doi:10.1089/109287502320963373.

[22] Bacchin, P., Meireles, M. and Aimar, P. "Modelling of filtration: from the polarised layer to deposit formation and compaction". Desalination 145, 139-146 (2002) doi:10.1016/S00119164(02)00399-5.

[23] Shamsuddin, N., Cao, C., Starov, V. M. and Das, D. B. "A comparative study between stirred dead end and circular flow in microfiltration of China clay suspensions". Water Sci. Technol. 
Water Supply (2016) doi:10.2166/ws.2015.158.

[24] Shamsuddin, N., Das, D. B. and Starov, V. M. "Filtration of natural organic matter using ultrafiltration membranes for drinking water purposes: Circular cross-flow compared with stirred dead end flow". Chem. Eng. J. (2015) doi:10.1016/j.cej.2015.04.075.

[25] ZHOU Ming,WANG Hongbo,WANG Yinlin, G. W. "Characterization of porosity of nanofiber membrane based on image processing technology". J. Text. Res. 33, 20-23 (2012).

[26] Anwar, Fahmi, and G. Arthanareeswaran. "Silver nano-particle coated hydroxyapatite nanocomposite membrane for the treatment of palm oil mill effluent." Journal of Water Process Engineering 31 (2019): 100844. doi: 10.1016/j.jwpe.2019.100844

[27] Flores, M. and Zafaralla, M. "Macroinvertebrate composition, diversity and richness in relation to the water quality status of Mananga River, Cebu, Philippines". Philipp Sci Lett (2012).

[28] Rajabi, H., Ghaemi, N., Madaeni, S. S., Daraei, P., Khadivi, M. A. and Falsafi, M. "Nanoclay embedded mixed matrix PVDF nanocomposite membrane: Preparation, characterization and biofouling resistance". Appl. Surf. Sci. (2014) doi:10.1016/j.apsusc.2014.05.185.

[29] "The stability of viscous flow between horizontal concentric cylinders". Proc. R. Soc. London. Ser. A. Math. Phys. Sci. (1959) doi:10.1098/rspa.1959.0091.

[30] Dean, W. R. "Fluid Motion in a Curved Channel". Proc. R. Soc. A Math. Phys. Eng. Sci. (1928) doi:10.1098/rspa.1928.0205.

[31] Boussu, Katleen, Bart Van der Bruggen, A. Volodin, Johan Snauwaert, Christian Van Haesendonck, and Carlo Vandecasteele. "Roughness and hydrophobicity studies of nanofiltration membranes using different modes of AFM." Journal of colloid and interface science 286, no. 2 (2005): 632-638. doi: 10.1016/j.jcis.2005.01.095

[32] Angelico, R., Ceglie, A., He, J. Z., Liu, Y. R., Palumbo, G. and Colombo, C. "Particle size, charge and colloidal stability of humic acids coprecipitated with ferrihydrite". Chemosphere 99, 239-247 (2014) doi:10.1016/j.chemosphere.2013.10.092. 
484 [32] Anirudhan, T. S., Suchithra, P. S. and Rijith, S. "Amine-modified polyacrylamide-bentonite 485 composite for the adsorption of humic acid in aqueous solutions". Colloids Surfaces A 486 Physicochem. Eng. Asp. 326, 147-156 (2008) doi:10.1016/j.colsurfa.2008.05.022.

487 [34] Ahmad, Abdul Latif, Wen Yu Pang, Zulfida Mohamad Hafis Mohd Shafie, and Nur Dina 488 Zaulkiflee. "PES/PVP/TiO2 mixed matrix hollow fiber membrane with antifouling properties 489 for humic acid removal." Journal of Water Process Engineering 31 (2019): 100827. doi: 490 10.1016/j.jwpe.2019.100827

491 


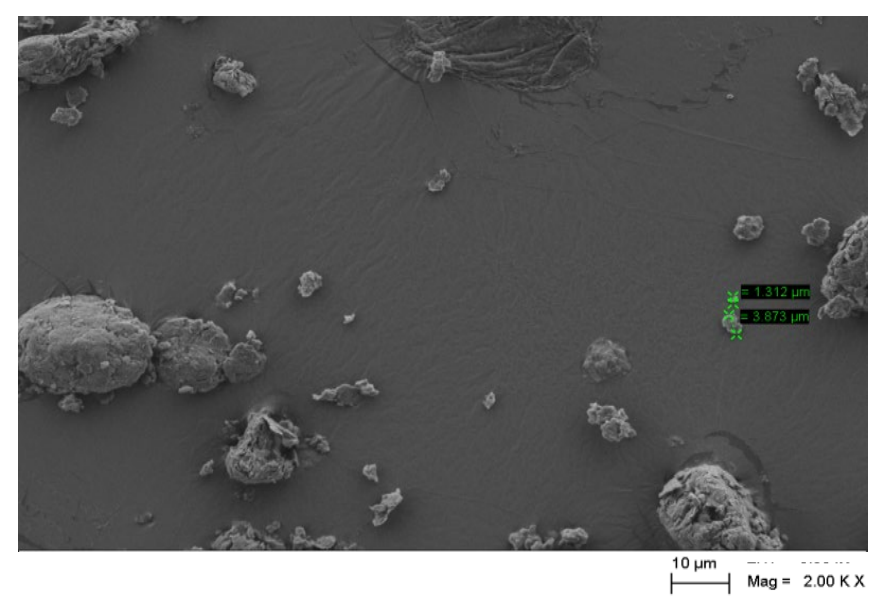

Fig. 1. SEM image of nanoclay particles.

501

502

503

504

505

506

507

508

509

510

511

512

513

514

515

516

517 


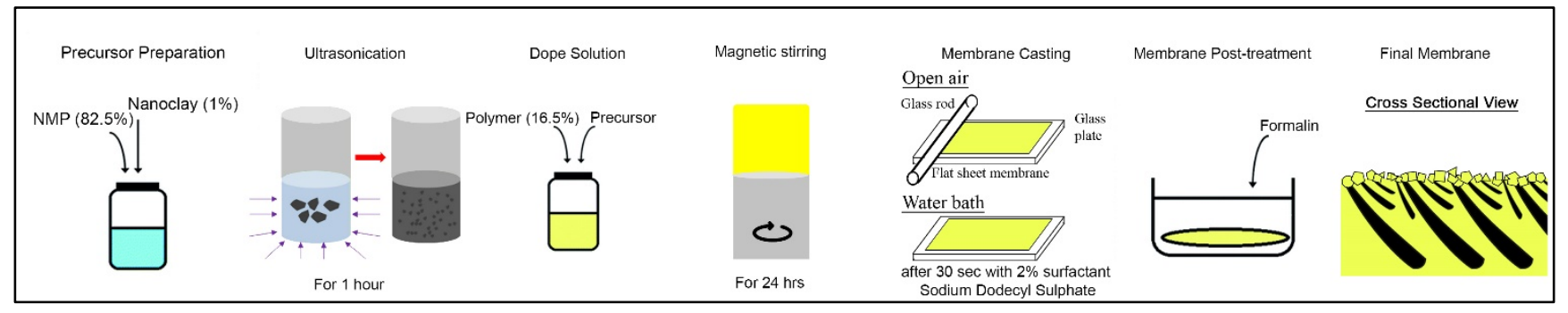

Fig. 2. Schematic representation of fabrication process of in-house membranes.

522

523

524

525

526

527

528

529

530

531

532

533

534

535

536

537

538

539

540 

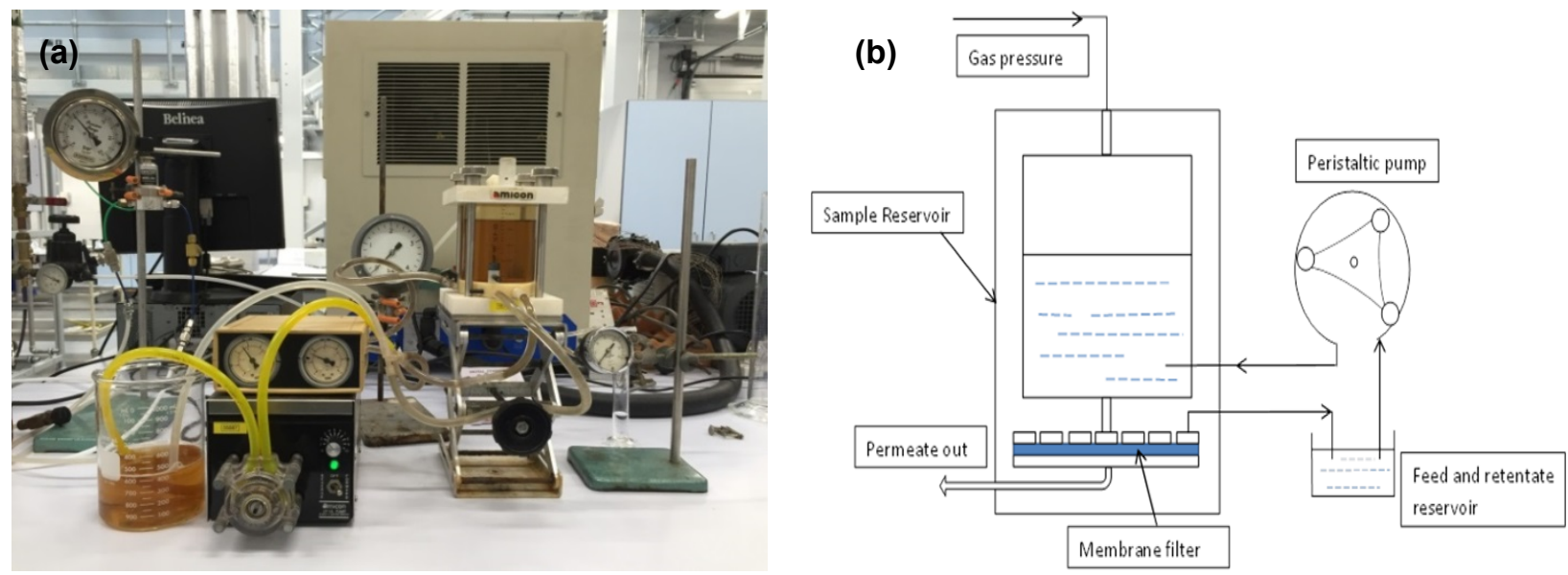

Fig. 3. (a) The experimental set up of the circular crossflow filtration system, (b) the side view of 

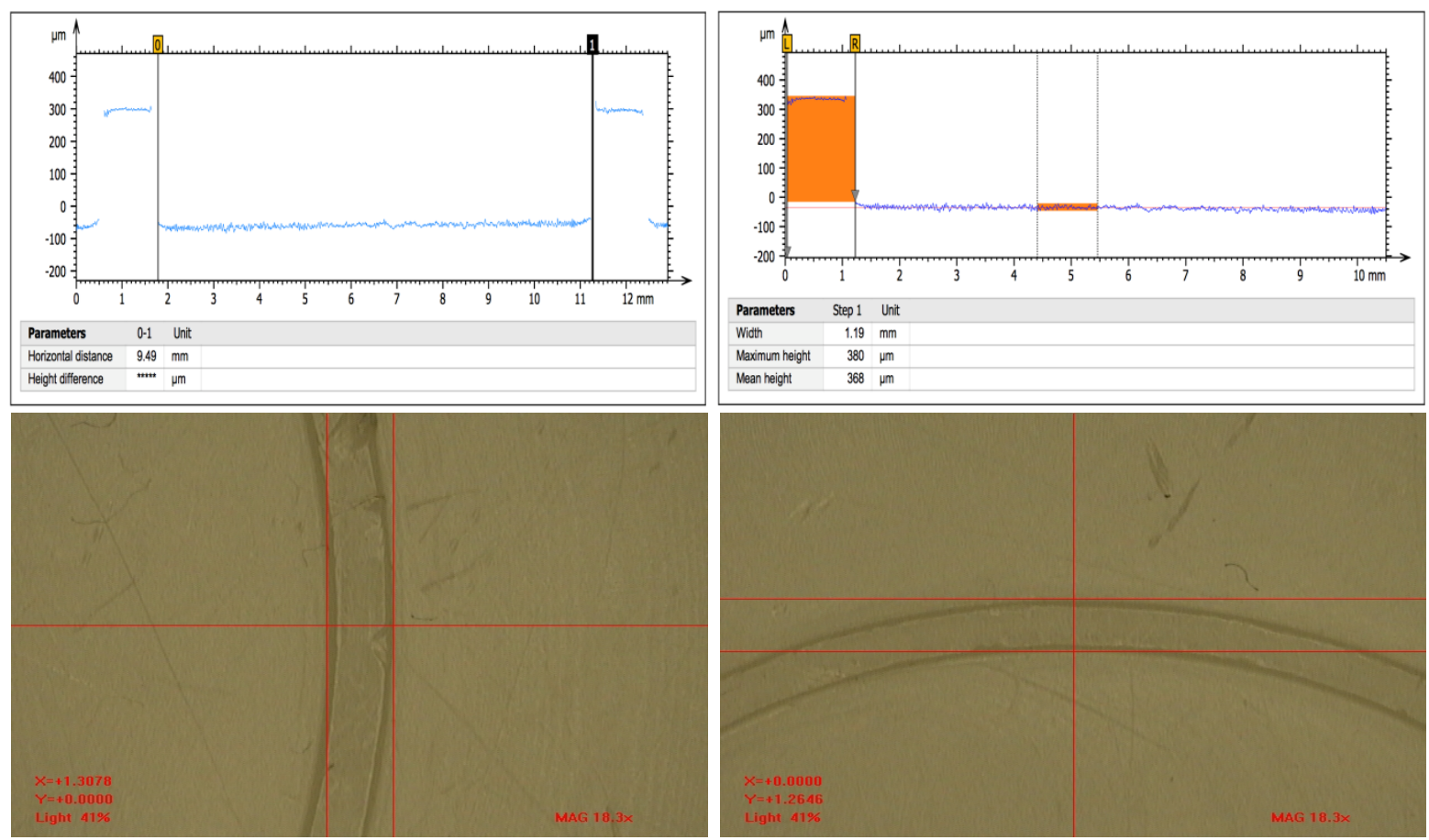

566 Fig. 4. Depth profile of the plate consisting of fluidic channels used in the filtration experiments. 

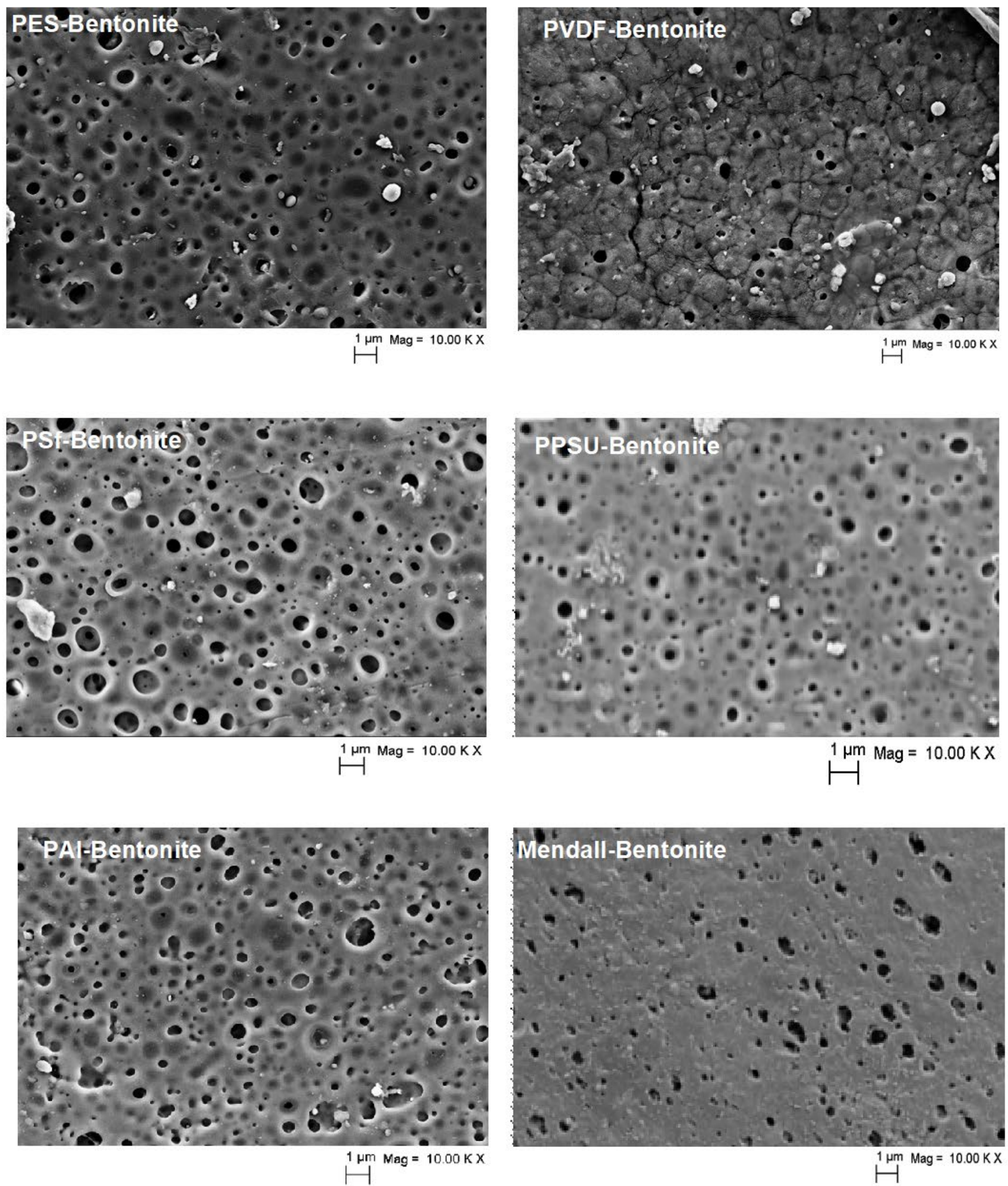

Fig. 5. Top surface morphology of in-house membranes 

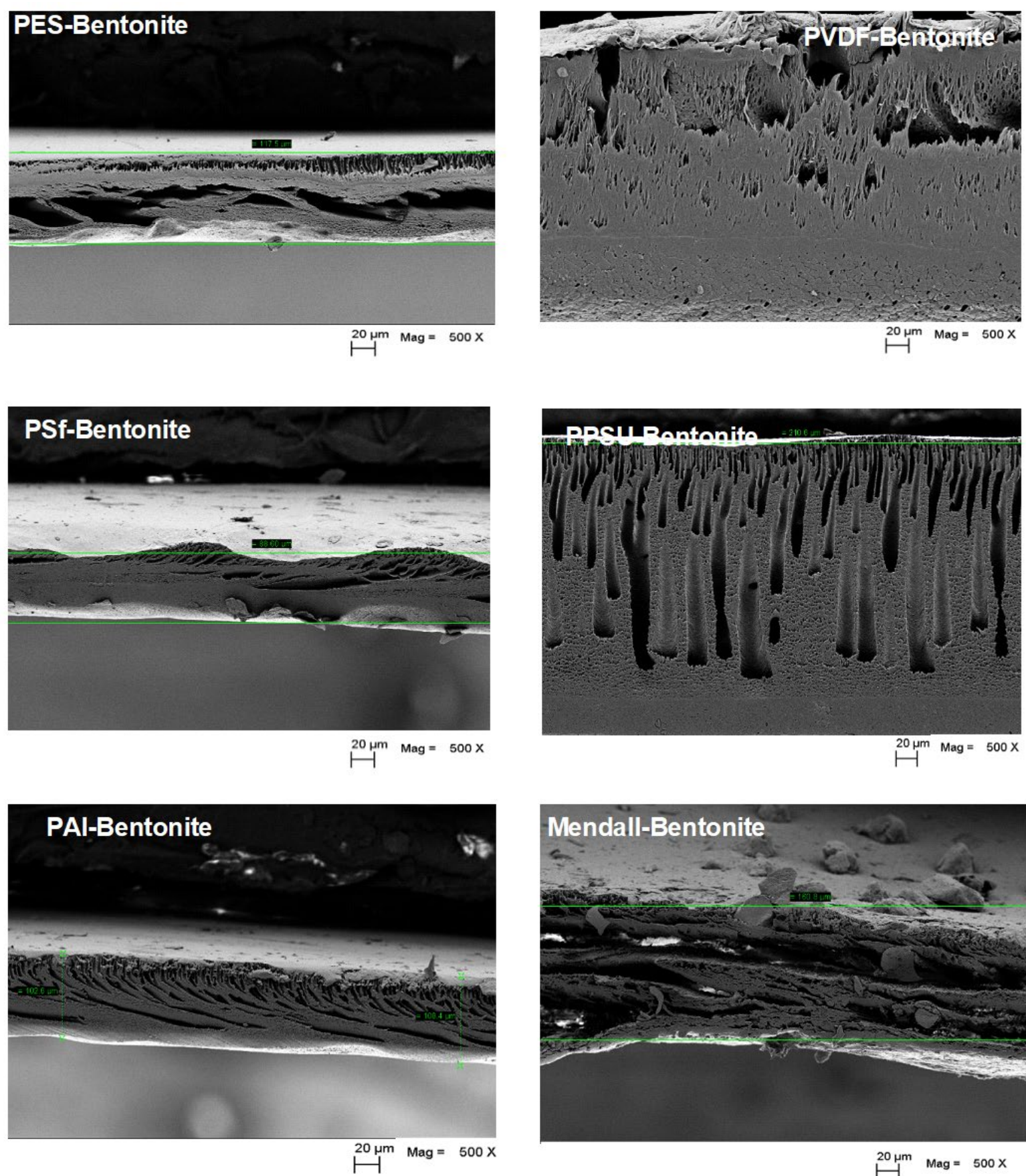

Fig. 6. Cross sectional morphology of in-house membranes 

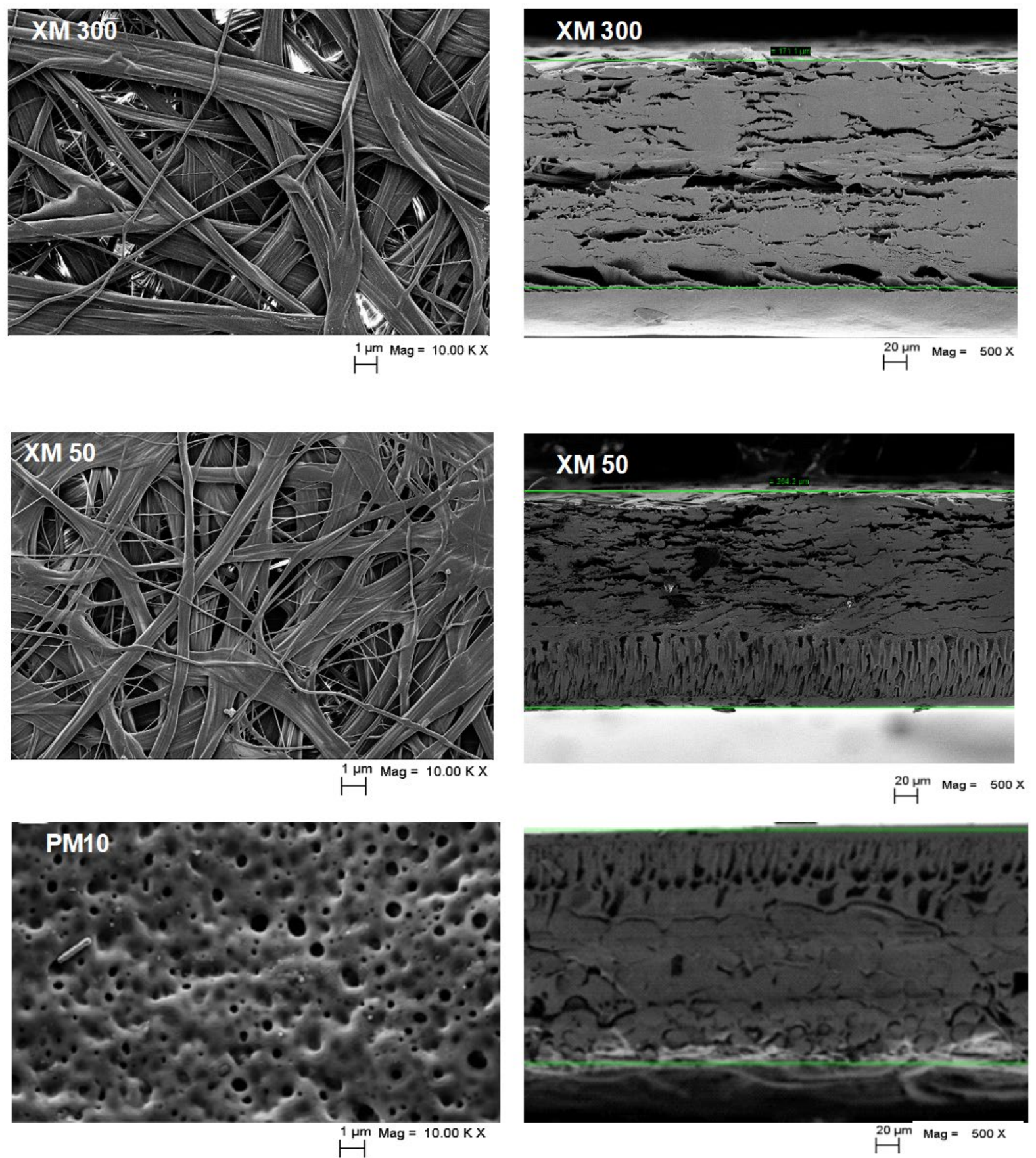

Fig. 7. Surface and cross-sectional morphology of commercial membranes 


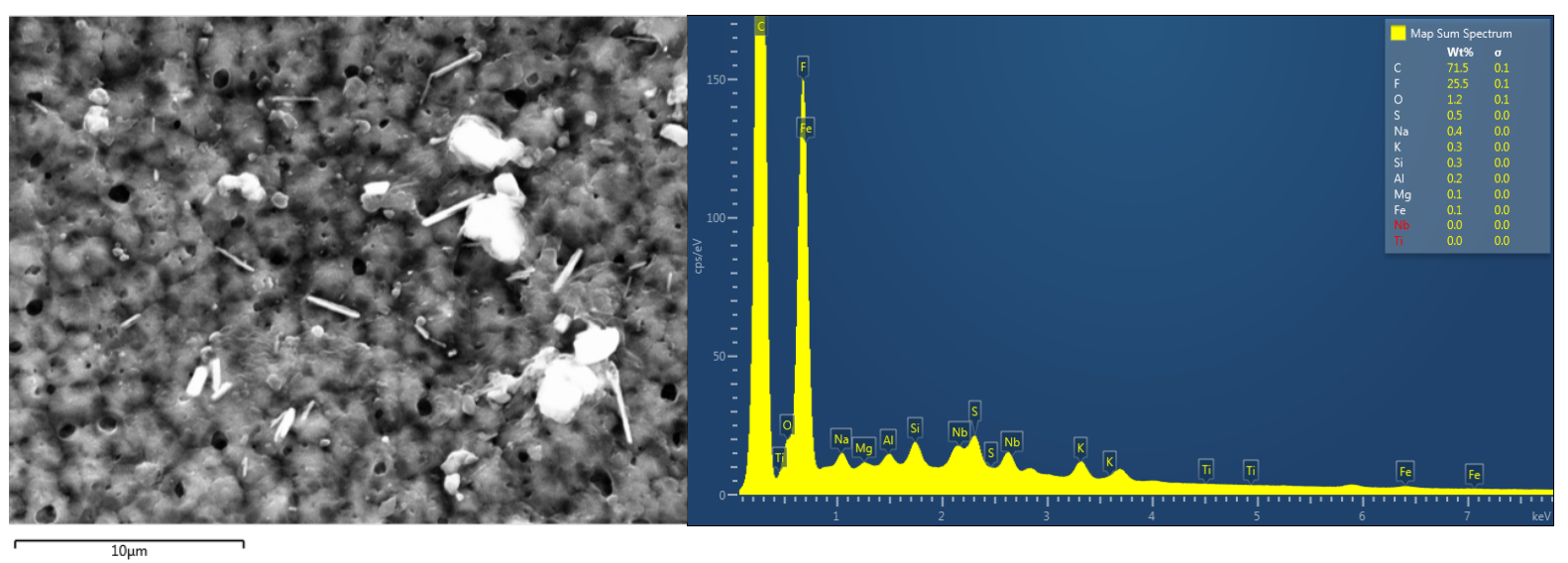

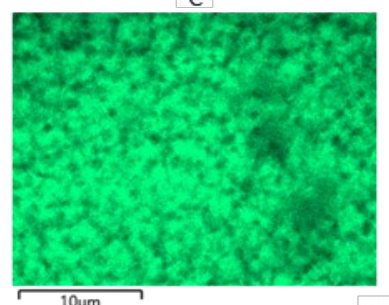

$\mathrm{Si}$
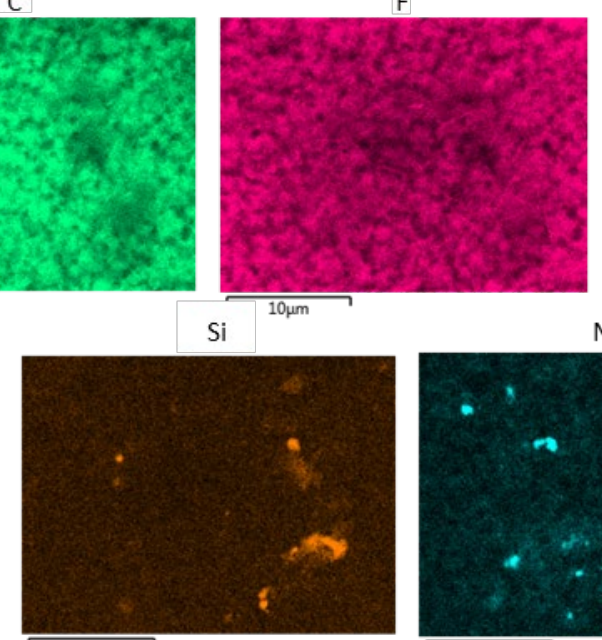

K
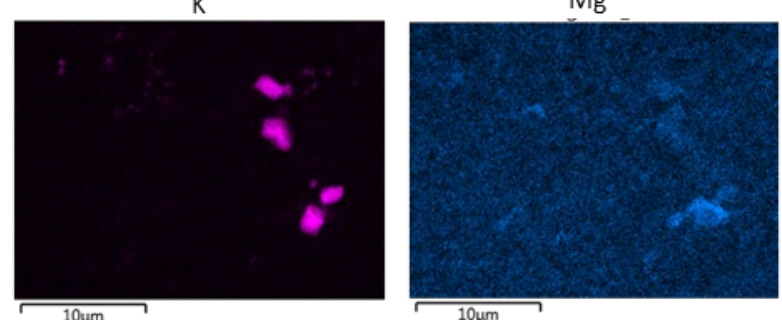

0

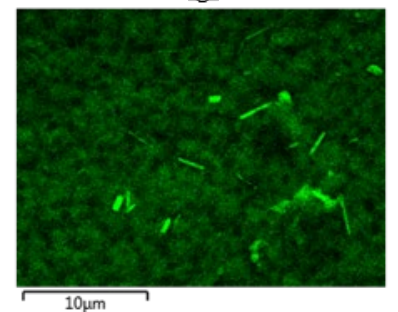

$\mathrm{Na}$
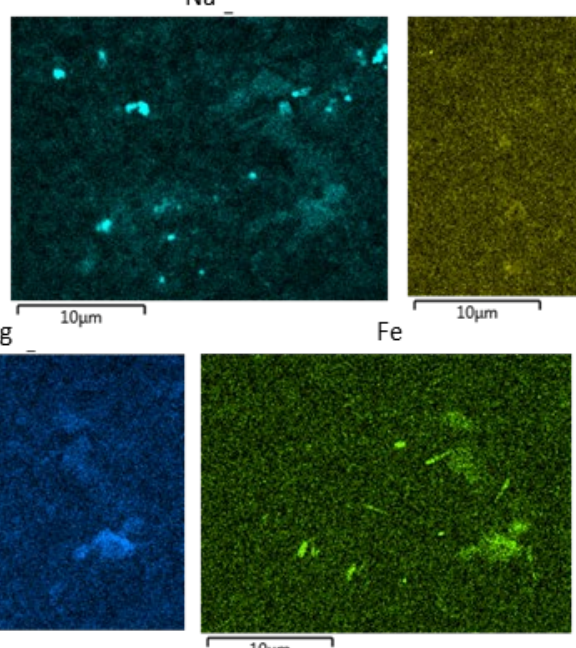

S

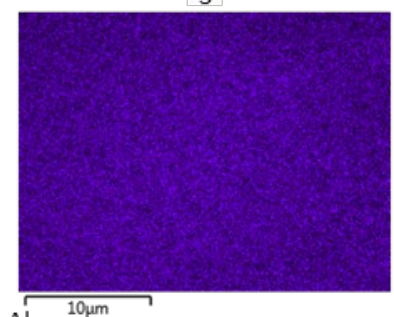

Al $10 \mathrm{~mm}$

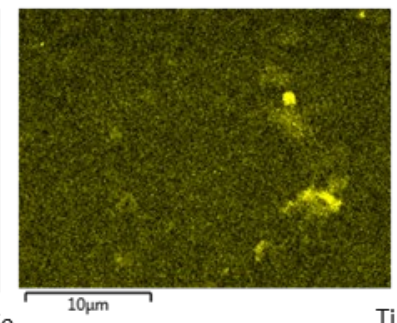

$\mathrm{Ti}$

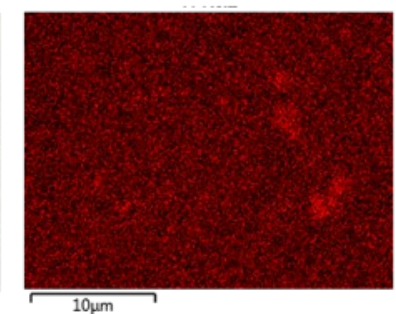

592 Fig. 8. EDS mapping of components for PVDF membrane at 10kX magnification, the element of concern is shown on the top of each image. 


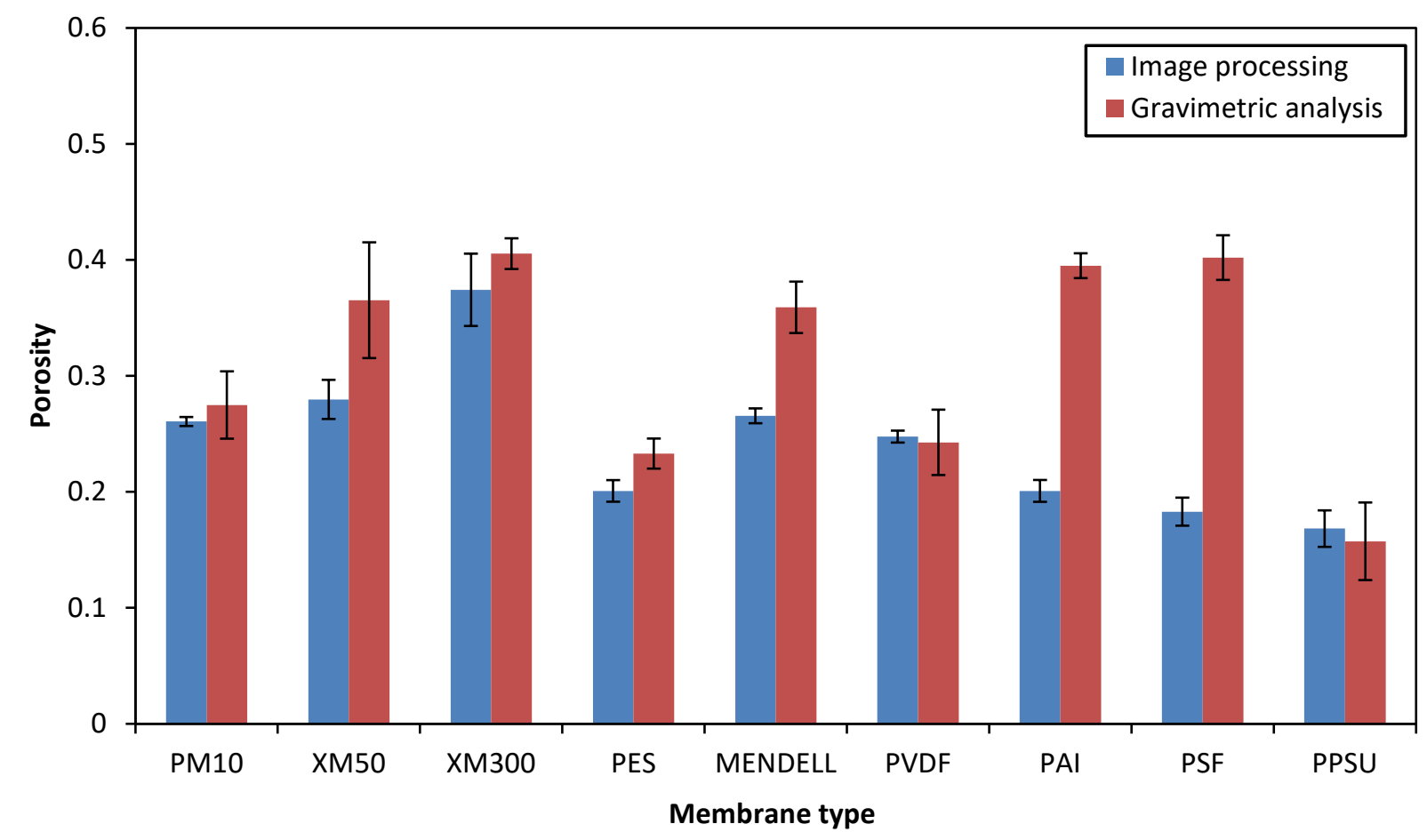

597 Fig. 9. Porosity of the membranes calculated through experiments and image processing (SD from duplicate samples from one of three representative experiments). 


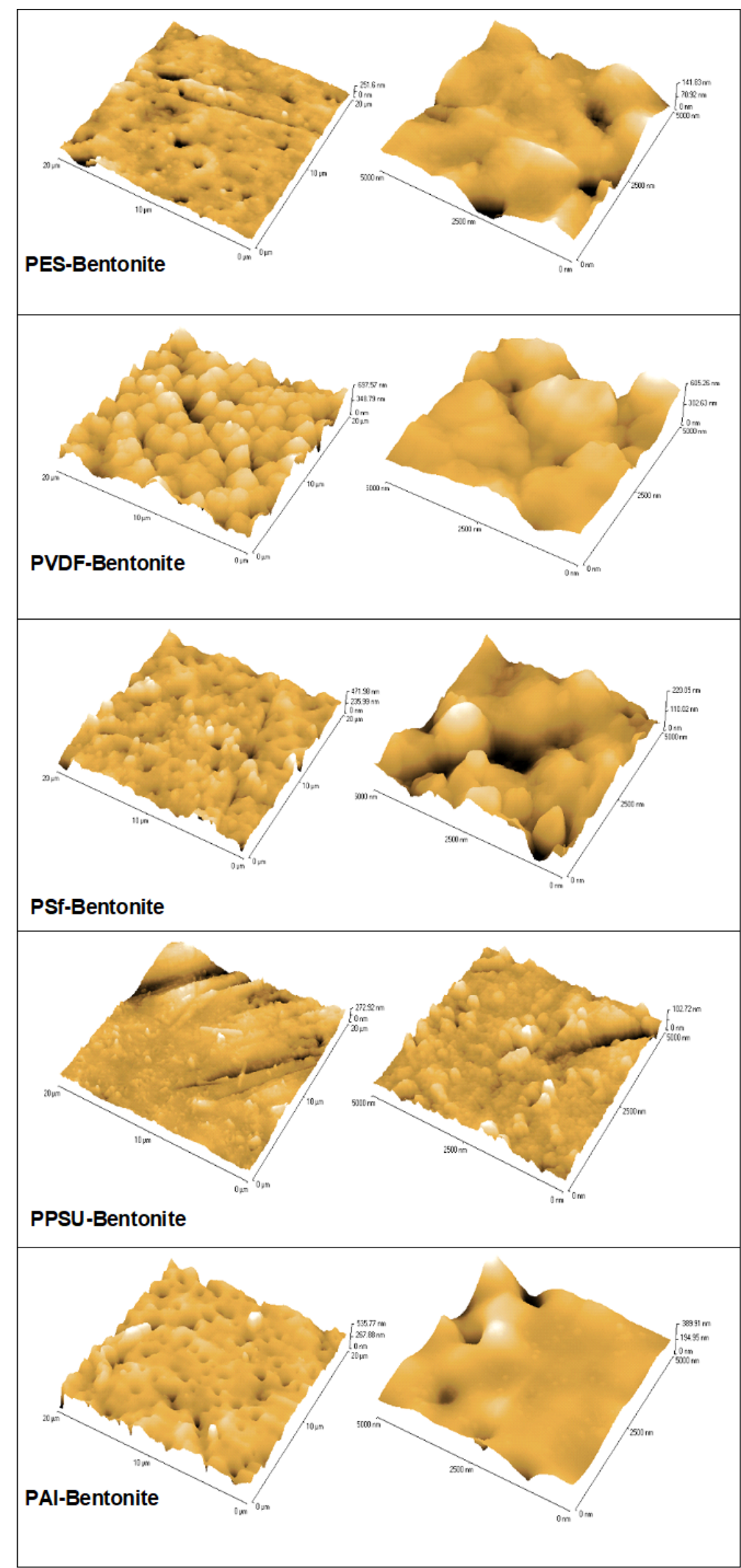

Fig. 10. AFM surface images of in-house membranes 


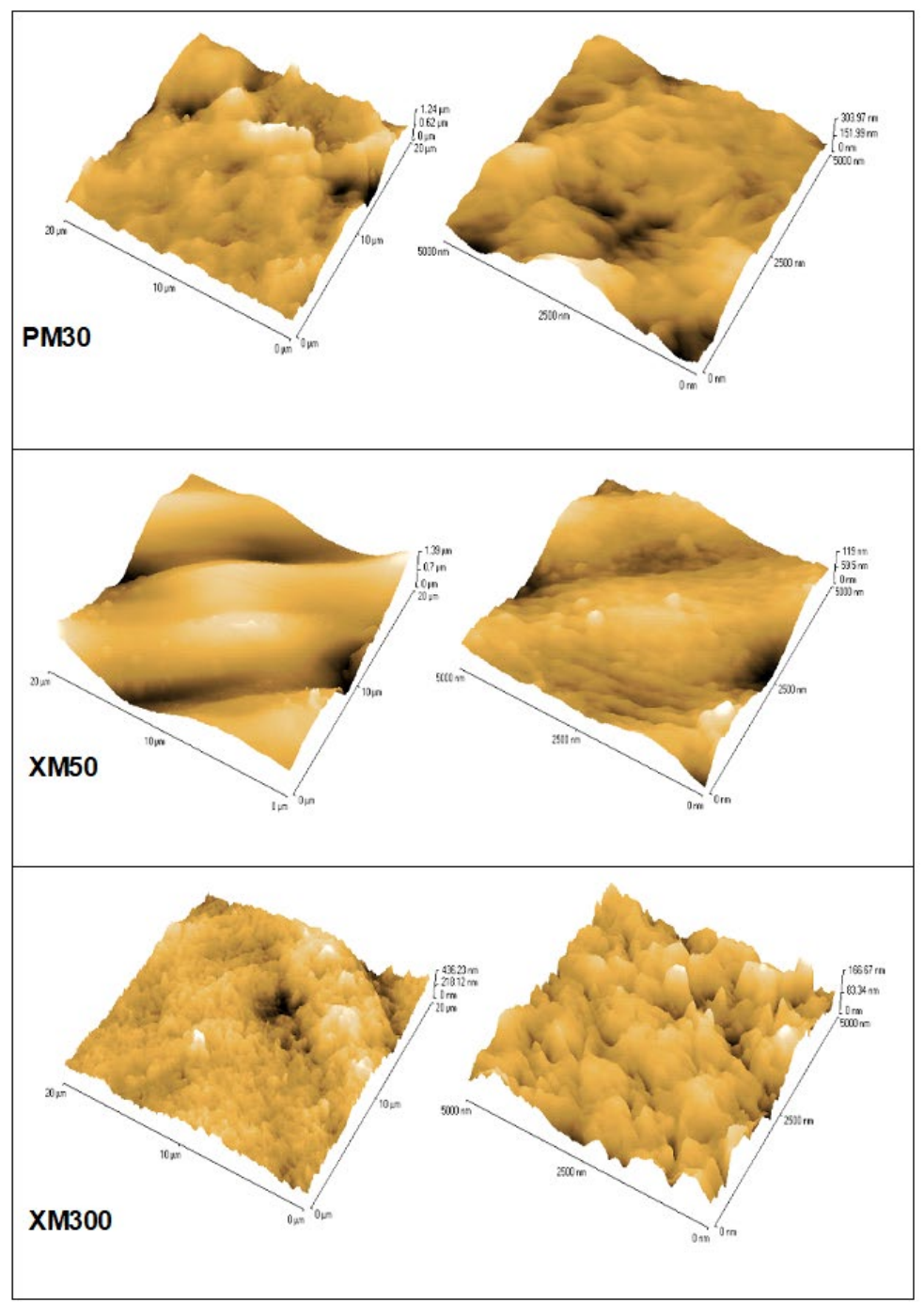

Fig. 11. AFM surface images of commercial membranes 


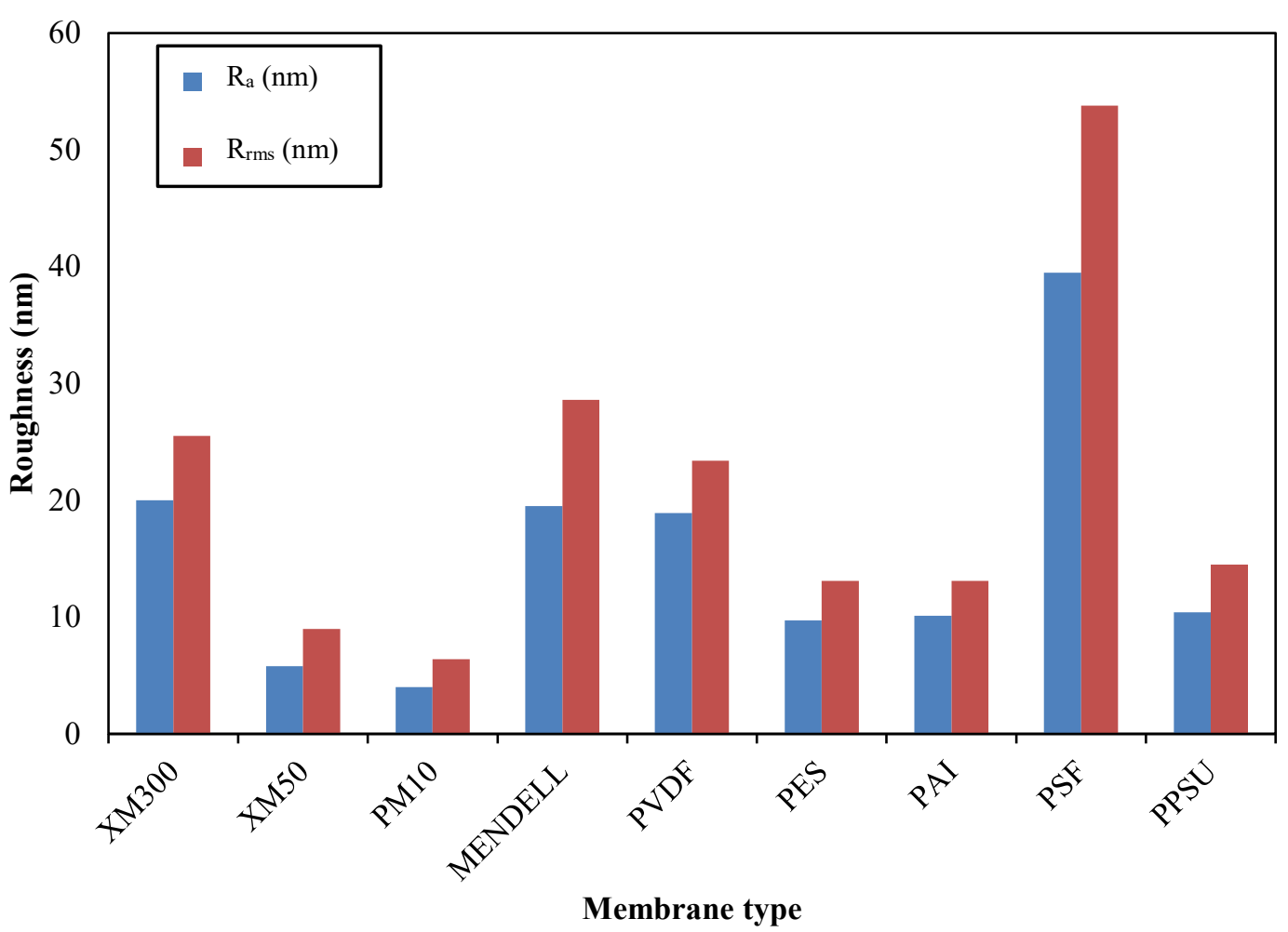

Fig. 12. Surface roughness of in-house and commercial membranes

625 

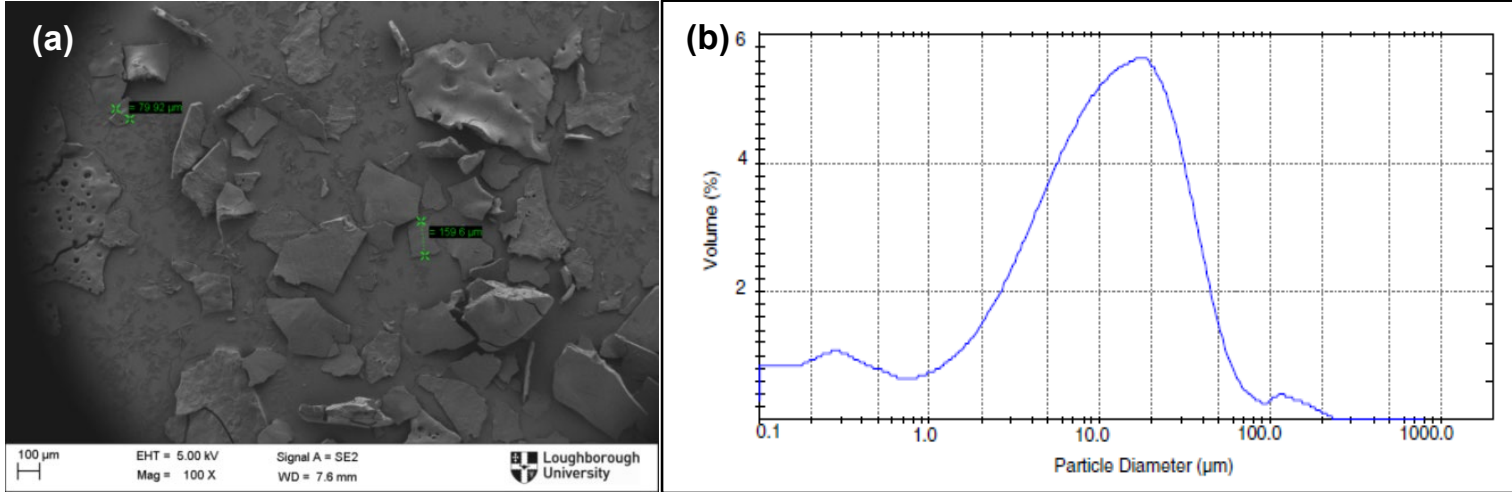

Fig. 13. (a) SEM micrographs of dry humic acid particles, (b) humic acid particle size range. 

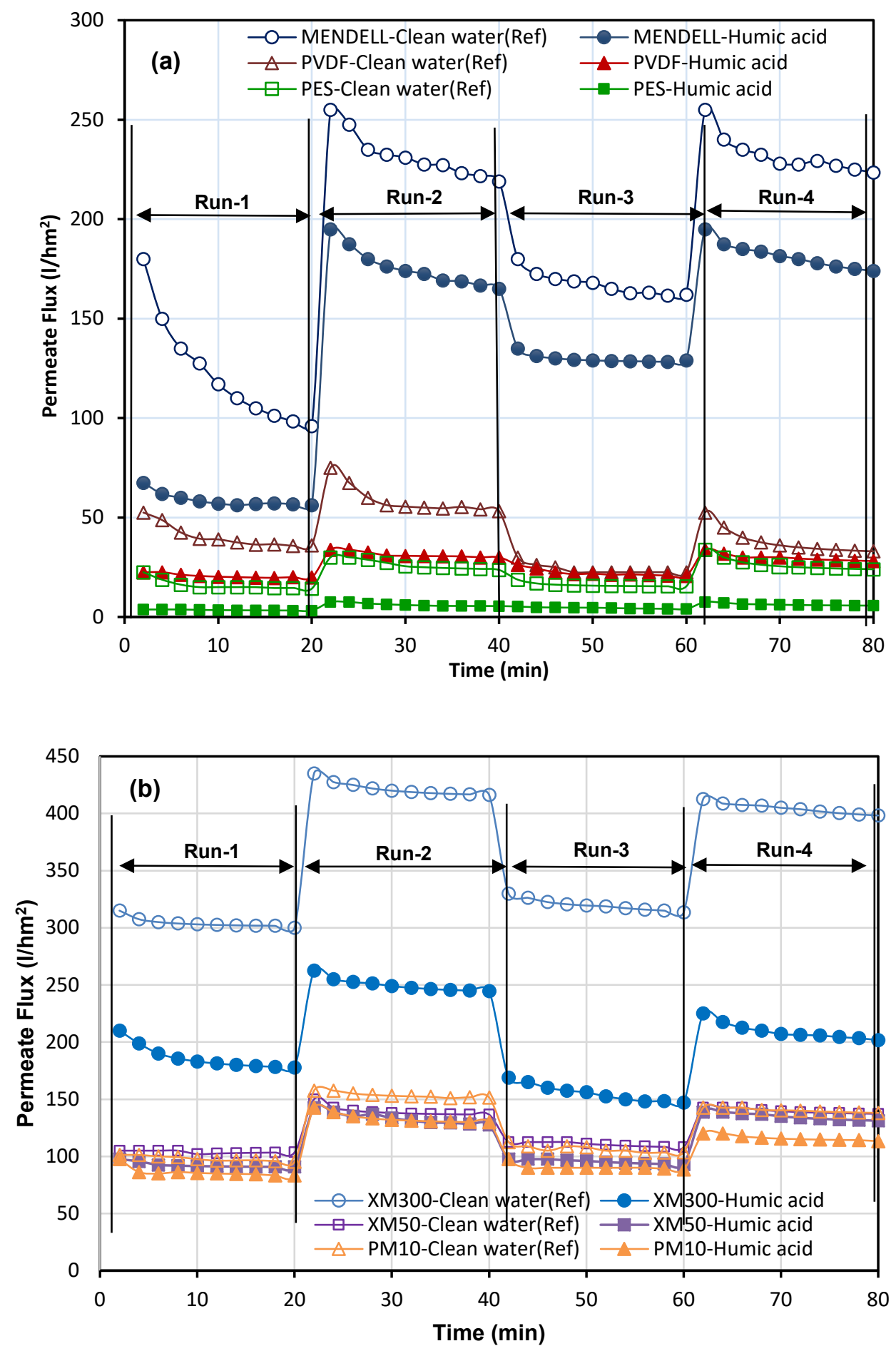

Fig. 14. Permeate flux and fouling of (a) in-house membranes (porous membrane), (b) commercial membranes (fibrous membrane). 


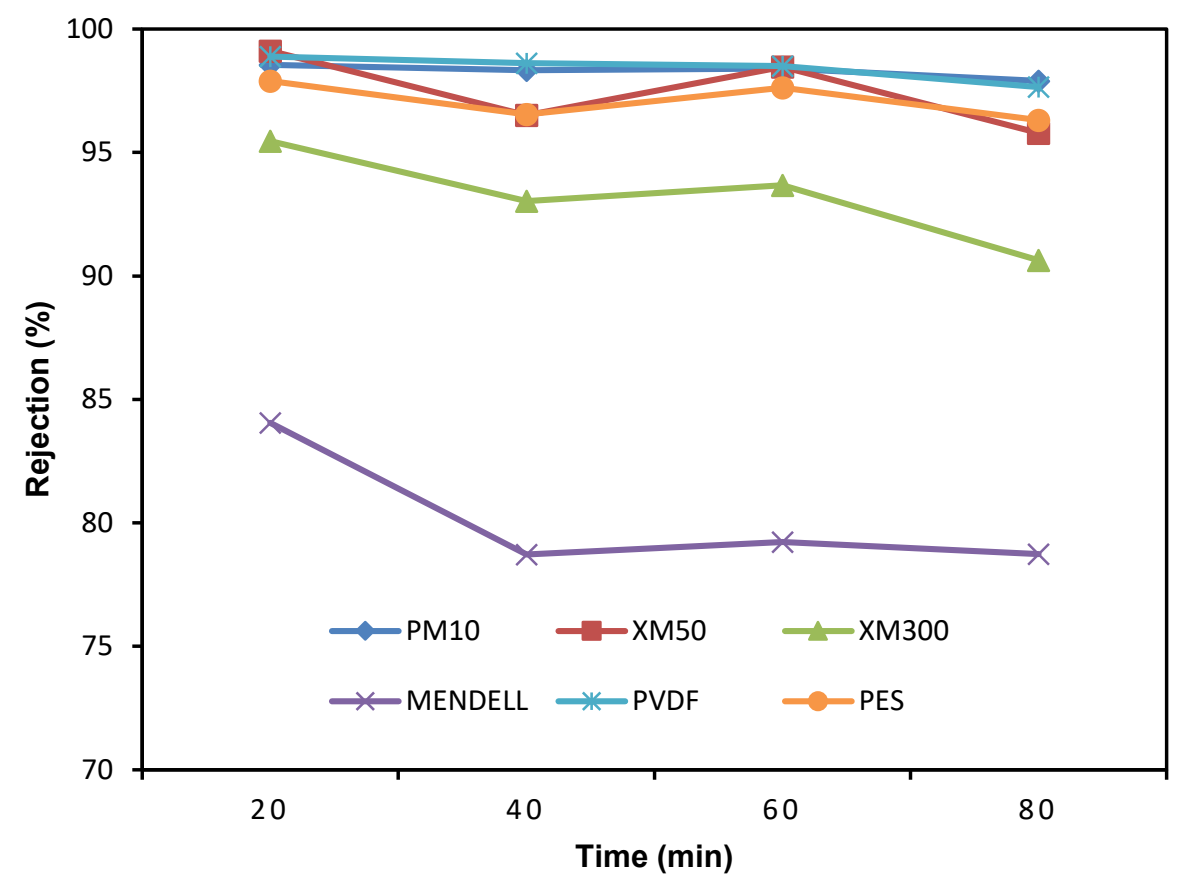

634

635 Fig. 15. Percentage rejection of humic acid for various membranes with respect to time (SD from 636 duplicate samples from one of two representative experiments).

637 


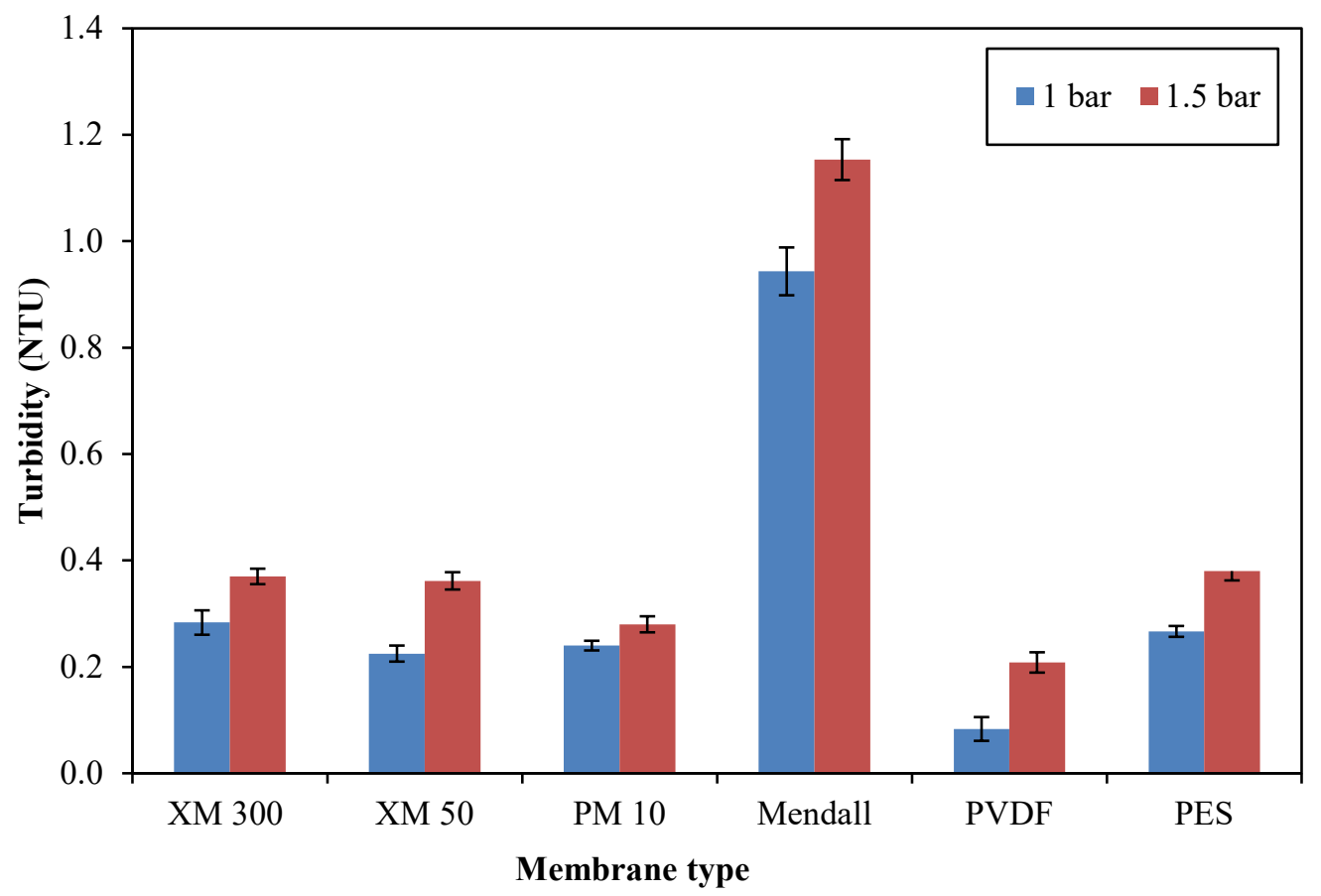

639

640 Fig. 16. Turbidity of the permeate for various membranes at two different pressures (SD from duplicate samples from one of three representative experiments). 


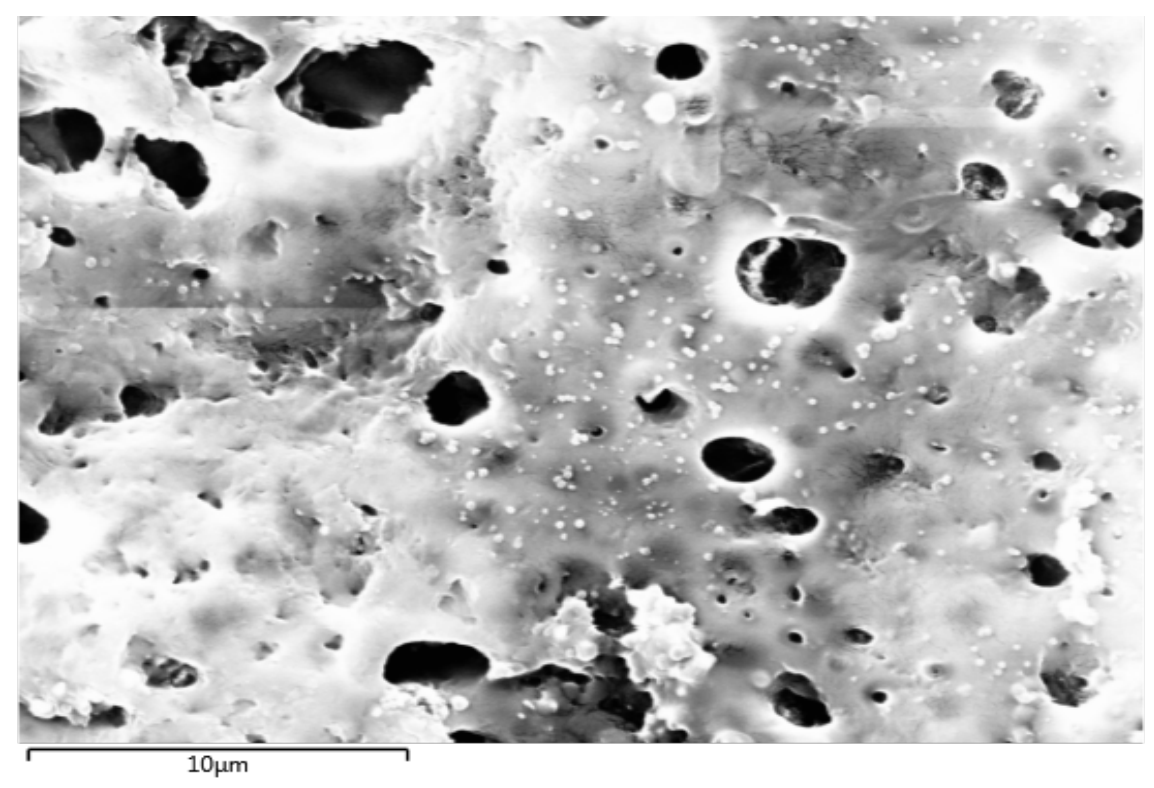

646 Fig. 17. Humic acid particles on the surface of membrane Mendall ${ }^{\mathrm{TM}}$ polysulfone after filtration. 
648 Table. 1: Average Pore Size, fiber-fiber distance, fiber diameter of in-house and commercial 649 membranes

650

\begin{tabular}{|c|c|c|c|c|}
\hline \multirow{2}{*}{ Membrane Type } & \multirow{2}{*}{$\begin{array}{c}\text { Average Pore } \\
\text { Size }(\mu \mathrm{m})\end{array}$} & \multirow{2}{*}{$\begin{array}{c}\text { Average Fiber-Fiber } \\
\text { Distance }(\mu \mathrm{m})\end{array}$} & \multicolumn{2}{|c|}{ Average Fiber.1 } \\
\hline & & & \multicolumn{2}{|c|}{ Diameter $(\mu$ ศ下) } \\
\hline PM10 & $0.004 \pm 0.134$ & $3.093 \pm 1.909$ & \multicolumn{2}{|c|}{$3.293 \pm 2.20653$} \\
\hline XM50 & $0.0053 \pm 0.210$ & $9.958 \pm 5.723$ & \multicolumn{2}{|c|}{$5.484 \pm 5.07654$} \\
\hline XM300 & $0.0086 \pm 0.132$ & $15.640 \pm 12.724$ & \multicolumn{2}{|c|}{$9.352 \pm 8.676 \bar{p} 5$} \\
\hline Poly-ether-sulfone & $0.553 \pm 0.272$ & -- & -- & 656 \\
\hline Mendall $^{\mathrm{TM}}$ & $8.378 \pm 4.196$ & -- & -- & 657 \\
\hline polysulfone & & & & 658 \\
\hline Polyvinylidene & $0.481 \pm 0.230$ & -- & -- & 659 \\
\hline fluoride & & & & 660 \\
\hline Poly amide imide & $0.463 \pm 0.242$ & -- & -- & 661 \\
\hline Polysulfone & $0.663 \pm 0.349$ & -- & -- & 662 \\
\hline Polyphenylsulfone & $0.344 \pm 0.218$ & -- & -- & $\begin{array}{l}664 \\
665\end{array}$ \\
\hline & & & & 666 \\
\hline
\end{tabular}


690

691

692

693 *Corresponding author (E-mails address: arthanaree10@yahoo.com, D.B.Das@lboro.ac.uk)

\section{Supporting Information}




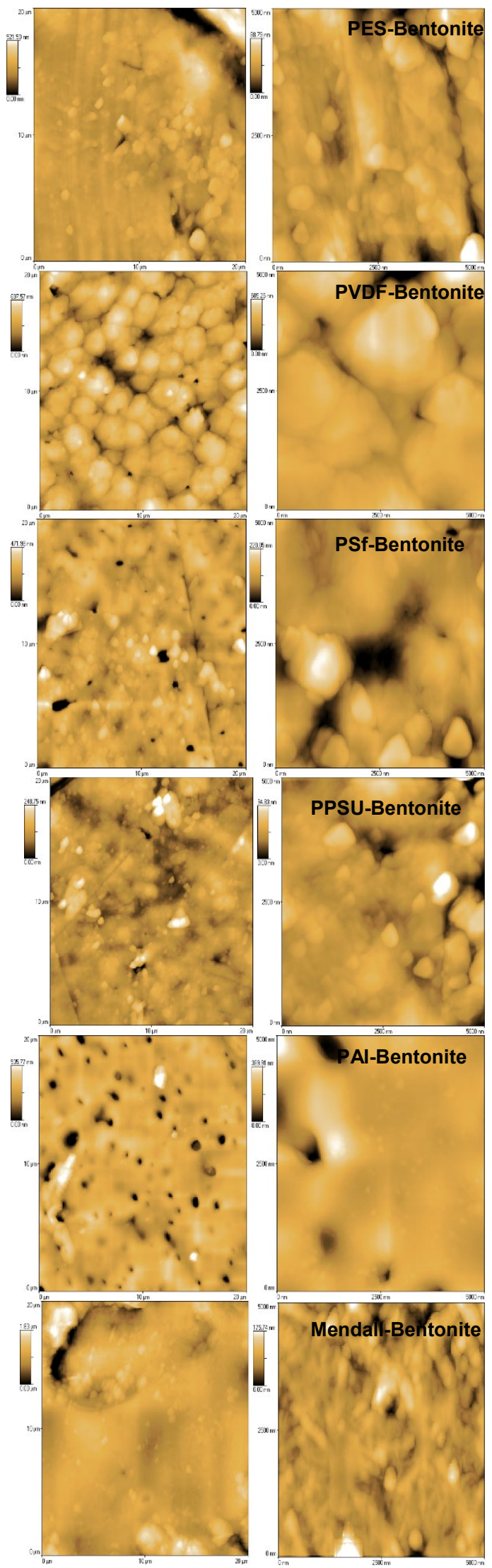




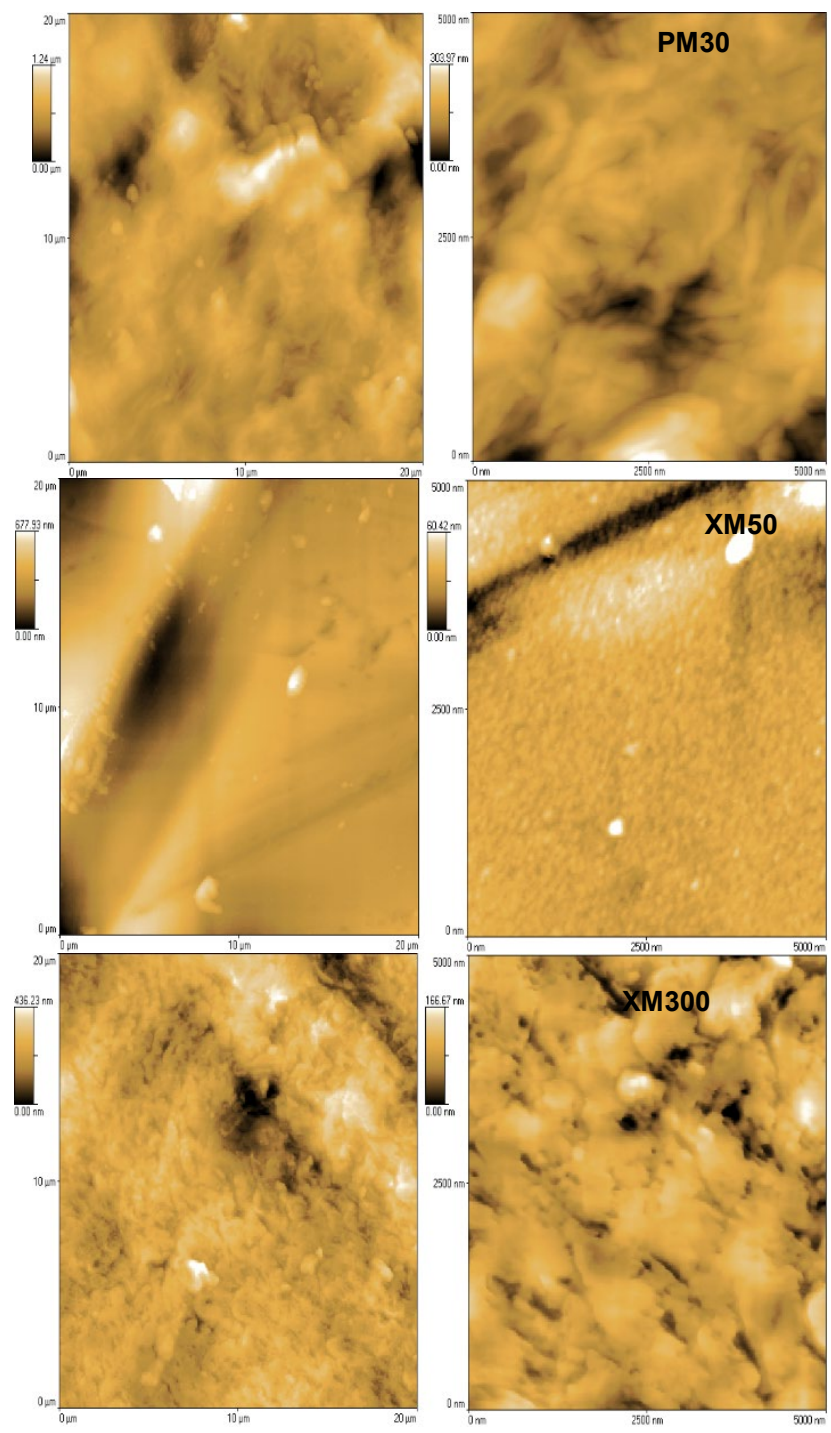

697

698

699

700 